\title{
ESTUDIOS
}

\section{GEORGES CUVIER \\ ¿UN NOMBRE OLVIDADO EN \\ LA HISTORIA DE LA FISIOLOGÍA?}

\section{Gustavo Caponi}

Universidade Federal de Santa Catarina, Brasil

\section{RESUMEN}

Institucionalmente, el programa de Cuvier se desarrolló en un espacio ajeno al de las ciencias medicas; pero, desde una perspectiva epistemológica sus preocupaciones teóricas coincidían con aquellas que guiaron gran parte de ese dominio de investigaciones. Su anatomía comparada era un recurso para desarrollar la fisiología; ciencia que él consideraba parte de una historia natural entendida como fisica particular.

PALABRAS CLAVE: G. Cuvier, historia natural, anatomía comparada, fisiología, condiciones de existencia.

\section{SUMMARY}

Institutionally, Cuvier's program has developed in an area foreign to the medical sciences; nonetheless, from a epistemological point of view, his theoretical concerns coincided with those that guided a big part of this field of research. His comparative anatomy was a resource for the development of physiology, science that was considered by him as part of a natural history understood as particular physics.

KEY WORDS: G. Cuvier, natural history, comparative anatomy, physiology, conditions of existence. 


\section{PRESENTACiÓN}

El objetivo de este trabajo no es rescatar de un injusto olvido, putativos y tal vez cruciales, aportes a la fisiología que Cuvier habría hecho paralelamente a sus trabajos como historiador natural. Mi objetivo, muy lejos de eso, es mostrar que, apelando a la anatomía comparada, Cuvier no buscaba otra cosa que desarrollar, e incluso extender al estudio de seres extintos, ese capítulo fundamental de la historia natural que para él era la fisiología. Para ello analizaré el concepto cuvieriano de historia natural, su idea de la anatomía comparada y su concepto de condiciones de existencia.

Sobre la anatomía comparada diré algo que tal vez sea obvio pero de lo cual no se han sacado las debidas consecuencias: descreyendo de la posibilidad de llegar demasiado lejos con el estudio experimental de los seres vivos, Cuvier creía encontrar en esa disciplina el único recurso metodológico posible para producir un genuino y profundo saber fisiológico. Así, partiendo de un análisis del concepto de función que encontramos en la obra de Cuvier y defendiendo una interpretación fisiológica del principio de las condiciones de existencia, propondré una revisión bastante radical de la idea que nos hacemos del lugar de Cuvier en la historia de las ciencias de la vida.

Sostendré que, aunque desde una perspectiva institucional el programa de Cuvier se desarrolló en un espacio ajeno al de la tradición médica, desde una perspectiva epistemológica sus objetivos teóricos coincidían con las preocupaciones fisiológicas que guiaron a esa tradición. Así, en lugar de pensar a Cuvier como un naturalista pre-darwiniano sugeriré la posibilidad de pensarlo como algo más próximo a un eslabón entre Harvey y Claude Bernard.

\section{CUVIER EN LA HISTORIOGRAFÍA ACTUAL DE LA BIOLOGÍA}

Ernst Mayr (1988) y François Jacob (1973) no se equivocan: la biología moderna es un continente dividido en dos dominios generales de indagación. Uno es el dominio de la biología funcional: ese conjunto de disciplinas ocupadas en estudiar, por métodos generalmente experimentales, las causas próximas que actuando a nivel del organismo individual nos explican cómo los fenómenos vitales se encadenan e integran en la constitución de esas estructuras. El otro es el dominio de la biología evolutiva; es decir: ese otro conjunto de disciplinas que, siguiendo básicamente métodos comparativos e inferencias históricas, se consagran a la reconstrucción de las causas remotas que actuando a nivel de las 
poblaciones nos explicarían por qué cada una de estas evolucionan o evolucionaron en el modo en que efectivamente lo hacen y lo hicieron ${ }^{1}$.

Cada una de estas biologías, apunta Jacob (1973, p. 16), «aspira a instaurar un orden en el mundo viviente». En el caso de la primera, se trata de un orden intra-orgánico que atañe a las estructuras, funciones y actividades por medio de las cuales se integra y se constituye el viviente individual. En el caso de la segunda, en cambio, «se trata del orden por el que se ligan los seres, se establecen las filiaciones, se diseñan las especies»; se trata, en suma, de un orden inter-orgánico. Puede decirse, entonces, que si una «se interesa por el sistema que forma cada ser vivo», la otra «considera a los seres vivos como elementos de un vasto sistema que engloba toda la tierra» (Jacob, 1973, p. 16).

Por eso, mientras en el primer caso el biólogo analiza normalmente «un único individuo, un único órgano, una única célula, una única parte de la célula» (Mayr, 1998a, p. 89); en el segundo caso el organismo debe ser siempre considerado en función de sus relaciones con el medio y con los otros organismos (Jacob, 1973, p. 14). Así, mientras en este último dominio de investigaciones el biólogo puede continuar, en cierto modo, operando aún con los conceptos y los métodos de la historia natural y con relativa prescindencia del saber físico y químico (Jacob, 1973, p. 200); en el primero nos encontramos con un conjunto de investigaciones que, en virtud de sus propias pautas metodológicas y en función de los problemas estudiados, da lugar a un discurso sobre lo viviente que, por su contenido conceptual, tiende a aproximarse progresivamente a los discursos de la química y de la física.

Sin embargo, por pertinente y esclarecedora que esa distinción sea en lo referente a la constitución y al devenir de la biología moderna, debemos ser muy cuidadosos cuando intentamos utilizarla como clave para entender lo que fueron las ciencias de la vida antes del advenimiento del darwinismo y antes de la consolidación definitiva de la fisiología experimental en la segunda mitad del siglo XIX. Aunque a primera vista parezca lo contrario, puede ser un error pensar que esa distinción sea, como Mayr (1998a, p. 87; 1998b, p. 125) supone, una simple continuación de la separación entre medicina e historia natural con la que nos topamos cuando intentamos reconstruir el desarrollo de la biología anterior a 1860; y lo mismo puede decirse de la afirmación de Armand Ricqlès (1996, p. 8) según la cual esa distinción entre las dos biologías existiría desde la antigüedad.

1 Hemos analizado y profundizado distintos aspectos de esta oposición en Caponi (2000), Caponi (2001a) y en Caponi (2002). 
Pienso, en efecto, que, aunque cierta, la distinción entre la tradición médica y la tradición de los naturalistas no pasaba por los mismos ejes que hoy nos permiten distinguir entre biología funcional y biología evolutiva. En las ciencias de la vida anteriores a 1860 existía, sí, una separación institucional entre ambas tradiciones de investigación; pero la misma, no parecía obedecer a razones epistemológicas que guardasen algún isomorfismo o analogía con aquellas que hoy sustentan la distinción entre esos dos grandes dominios de la biología contemporánea.

Siguiendo ese esquema sugerido por Mayr y Ricqlès, pero tácitamente rechazado por Jacob $(1973$, p. 200) que correctamente data esa bifurcación en la segunda mitad del siglo XIX, toda la historia de nuestros modos de pensar lo viviente se habría desarrollado en dos teatros o foros relativamente autónomos y siguiendo dos líneas o vertientes paralelas que, sin mayores episodios de hostilidad entre ambas, habrían desembocado en esos dos grandes dominios de la biología moderna que Mayr llama biología funcional y biología evolutiva.

No sería correcto, sin embargo, atribuir esa idea sólo a esos dos autores. La misma es en realidad tan aceptada que, en general, ni siquiera se la enuncia; y, de ese modo, protegida por su carácter de certeza tácita, esa idea de las dos vertientes de las ciencias de lo viviente funciona como una justificación implícita de la distribución de temas y de capítulos que encontramos en la mayor parte de las historias de la biología. Distribución que, como es de esperar, propicia una lectura de la historia de las ciencias de lo viviente que acaba reforzando el mismo presupuesto que la motiva.

En una de esas vertientes, lo sabemos, se sucederían los grandes nombres de la fisiología, de la embriología experimental, de la citología, e incluso de la microbiología. Pero no podríamos nunca describir esta primera tradición como siendo puramente experimental: a ella, por lo general, se asocian también los nombres de aquellos que, siguiendo los métodos puramente observacionales de la anatomía y de la clínica, contribuyeron, sobre todo, al desarrollo de los conocimientos médicos. En la otra vertiente, en cambio, nos encontraríamos con los grandes nombres de lo que, en general, llamamos historia natural. Así, mientras en el caso de esta segunda tradición cabe hablar de una ciencia cuyos escenarios privilegiados fueron museos, jardines botánicos y zoológicos, exploraciones y viajes; en el caso de la primera tradición parece más adecuado hablar de una ciencia de laboratorios, de hospitales y de cátedras de medicina.

Desde esa perspectiva, hasta cierto punto útil y no carente de fundamentos, la fisiología de Bernard o Liebig sería la culminación de una larga dinastía en 
la que se contarían los nombres de Galeno, Harvey, Sthal, Haller, Spallanzani, Wolf y Bichat ${ }^{2}$. Mientras tanto, la biología evolutiva de Darwin y Wallace sería el punto de convergencia de una segunda tradición, que habiendo sido fundada por el propio Aristóteles, habría de ser mucho más tarde retomada por Linneo y por Buffon, para finalmente ser consolidada por los grandes naturalistas de fines del siglo XVIII e inicios del XIX como Lamarck, Geoffroy Saint-Hilaire y el propio Cuvier. Por eso, del mismo modo en que Bichat, pese a su vitalismo, suele ser colocado en la línea de sucesión que lleva a Claude Bernard; Cuvier pese a su fijismo, es siempre colocado en la línea de sucesión que lleva a la revolución darwiniana (cfr. Mayr, 1998 b, p. 125).

Y no juzgamos estar diciendo aquí nada demasiado antojadizo: en cualquier libro o artículo de historia de la biología, Cuvier es presentado como uno de los eslabones más respetables, pero también más antipáticos (Pellegrin, 1992, p. 6), de esa gran dinastía de naturalistas que acabamos de mencionar (por ejemplo: Duris \& Gohau, 1997; Greene, 1979; Le Guyader \& Génermont, 1998; Mayr, 1998a; Piveteau, 1981a). Más aún: en muchos de esas obras, el nombre de Cuvier aparece justamente en el capítulo sobre evolución (por ejemplo: Magner, 2002; Piveteau, 1961b; Ledesma Mateos, 2000; Smith, 1977); y es significativo que William Coleman (1964) haya subtitulado su obra George Cuvier Zoologist caracterizándola como A Study on the History of Evolutionary Theory. Además, es sobre todo en el dominio de la lengua francesa en donde, pese a las lúcidas reivindicaciones de Henri Daudin (1927) y Michel Foucault (1994[1970]), aun se insiste en citar el nombre de Cuvier para explicar el abortamiento o la postergación de una temprana aurora gálica del pensamiento evolucionista (por ejemplo: Buffetaut, 2001; Grimoult, 1998; Laurent, 2001).

Lo curioso, sin embargo, no está en el hecho de vincular a Cuvier con esa línea de desarrollo de las ciencias de la vida. Su obra fue uno de los grandes puntales del pensamiento anti-evolucionista y, al mismo tiempo, sus trabajos en anatomía comparada y en paleontología no dejaron de producir evidencias que también fueron aprovechadas por los propios evolucionistas (Coleman, 1964, p. 182). No puede haber duda, por eso, de que Cuvier se movía en un terreno que tenía mucho que ver con el espacio donde ese pensamiento evolucionista insistía en surgir: su ofensiva contra Lamarck (Corsi, 2001, p. 219 y ss.) y su polémica con Geoffroy Saint-Hilaire (Le Guyader, 1988, p. 123 y ss.) así lo atestiguan; y no es por acaso que, en su crítica de Darwin, Flourens (1864) se haya amparado precisamente en la autoridad de Cuvier.

2 Un ejemplo paradigmático de este modo de narrar la historia de la fisiología lo encontramos en SENET, A. (1956), L'homme a la découverte de son corps (roman de la physiologie), París, Plon. 
De hecho, y como apunta Coleman, «ciertos elementos del anti-transformismo de Cuvier fueron indispensables para la formulación de la teoría evolutiva». Tal el caso, por ejemplo, de sus argumentos fisiológicos contra la versión biológica de la escala de los seres: los mismos le allanaron el camino al darwinismo de un modo mucho más eficiente que las propias teorías de Lamarck (Daudin, 1927, p. 254). Además, con sólo citar sus preocupaciones paleontológicas, y más allá de las motivaciones a que estas obedecían, ya se puede justificar su relevancia para lo que más tarde vino a ser la biología evolutiva.

Pero aunque sea innegable que el mayor impacto y la mayor influencia del pensamiento de Cuvier tuvieron lugar en ese dominio de estudios que hoy integra el campo de la biología evolutiva, no deja de ser curioso cómo muchas veces se tiende a minimizar la importancia y la relevancia de su interés por la fisiología. De un modo u otro, el Cuvier paleontólogo acaba siempre eclipsando al Cuvier fisiólogo (cfr. por ejemplo, Rostand, 1985 [1945], p. 101 y ss.) y nadie se demora demasiado en analizar su vinculación con los fisiólogos de su época, ni nadie parece prestar atención a su posible influencia en los desarrollos de la fisiología posterior. Se insiste siempre en el contraste entre Bichat y Bernard; pero, por lo general, se desconsideran las coincidencias entre Bichat y Cuvier; y se ignoran las marcas que éste ultimo ha dejado en las obras del autor de la Introduction à l'étude de la Médecine Expérimentale (cfr. Caponi, 2001b, p. 399 y ss.).

Sin embargo, por inocente que parezca, ese modo de ver las cosas sólo se sostiene si desconocemos qué era lo que Cuvier entendía por historia natural y sobre todo si ignoramos cuál era el verdadero objetivo de su anatomía comparada. Más aún: si no ignoramos estas últimas e imprescindibles claves del pensamiento cuvieriano, podemos incluso llegar a concluir que, dadas las coordenadas epistemológicas que definían el espacio de la historia natural de toda la primera mitad del siglo XIX, los intereses de Cuvier estaban tal vez más cerca de los de Bichat que de los de Lamarck; y hasta cabría considerar que, en nuestra biblioteca, las Leçons d'anatomie comparée deberían estar tal vez más cerca de las Recherches de Bichat (1994a [1800]) y de las Leçons de Bernard (1878) que del Origin de Darwin (1859).

\section{EL CONCEPTO CUVIERIANO DE HISTORIA NATURAL}

Para Mayr, para Stephen Gould (1999, p. 284), y para todos nosotros, es cierto, la expresión 'historia natural' hoy sólo puede servir como un modo más literario, tal vez ligera pero elegantemente demodé, de aludir a la biolo- 
gía evolutiva en el sentido lato del término. Así, en su célebre The Nature of Natural History de 1950, Marston Bates (1990, p. 7) oponía esta disciplina a la fisiología, a la citología y a la bioquímica, todas ellas capítulos de la biología funcional; y nos decía que su objetivo era el estudio «de aquello que las plantas y los animales hacen, de cómo ellos reaccionan los unos frente a los otros y frente al ambiente y de cómo se organizan en agrupamientos mayores tales como poblaciones y comunidades».

La palabra 'naturalista' queda entonces hoy reservada, como lo apunta el editor de The American Naturalist (Grant, 2000, p. 4), para aludir a quien se ocupa de esos menesteres que hacen a la biología evolutiva. Como vemos, ni Gould, ni Bates, ni Peter Grant, se dieron nunca por enterados de la oposición entre biología e historia natural apuntada por Foucault (1968, p. 260) en Las palabras y las cosas; y ese descuido terminológico es comprensible: la expresión 'historia natural' acabó siendo muy adecuada para denominar esa parte de la biología en que se estudia precisamente esa historicidad de la vida y de la naturaleza que la propia historia natural de la época clásica jamás hubiese conseguido pensar (cfr. Foucault 1968, pp. 270-1).

Pero como sabemos, lo que Cuvier ( $c f r .1810$, p. 140 y ss.) y sus contemporáneos entendían por 'historia natural' era algo más amplio que aquello que nosotros entendemos: el estudio de los seres organizados era sólo una parte de una historia natural que, entre otras cosas, también debía ocuparse del estudio de los minerales y de las conformaciones terrestres (Cuvier, 1792, p. 2; 1810, p. 199). De hecho, durante los siglos XVIII y XIX, esa palabra servía para denotar algo muy próximo del conjunto de disciplinas que hoy solemos englobar bajo el rótulo de «ciencias de la vida y de la tierra»; y esto puede notarse en la obra de aquellos que consideramos como los grandes naturalistas de ese período: ni la geología o la mineralogía fueron ajenas a Linneo, a Buffon, a Lamarck, a Humboldt, a Cuvier o a Darwin; ni la distribución y las modificaciones de los seres vivos dejaron de suscitar el interés de Lyell (cfr. Laudan, 1987; Bowler, 1998).

Ese era, además, el espectro de investigaciones al que se consagraban la mayor parte de las cátedras creadas en 1793 cuando el Jardín Royal des Plantes de Paris deviene Muséum National d'Histoire Naturelle (Laissus, 1995, p. 20); y esos eran los temas que más páginas ocupaban en las revistas de historia natural que se publicaban a fines del siglo XIX (Grant, 2000, p. 3). Así, todavía a fines de ese siglo, un buen tratado de historia natural podía, y debía, incluir capítulos de mineralogía y geología ( $c f r$. por ejemplo, Tschermak \& Geike, 1894). Sin embargo, más que la multiplicidad y la amplitud de los temas y de los objetos que ocupaban la atención de la vieja historia natural (ver Buf- 
fon, 1749), lo que aquí debe interesarnos es la comprensión epistemológica que Cuvier, y sus contemporáneos, tenían de esa disciplina.

En este sentido, lo primero a ser apuntado es que el concepto cuvieriano de 'historia natural' no debe ser entendido en virtud de la oposición entre Historia Natural y Filosofía Natural que era corriente en la Inglaterra del siglo XVIII. Según esa polaridad, mientras la Filosofía Natural procuraba «la determinación de los principios operantes en el mundo físico», la Historia Natural se limitaba a «la descripción de la tierra y de sus producciones naturales» (Rehbock, 1983, p. 7). Esta última idea, que es propia de la tradición linneana (Duris, 1994, p. 16), ya había sido alevosamente desacatada por Buffon (Daudin, 1926a, p. 126; Greene, 1979, p. 126; Blanckaert, 1994, p. 60); y sería un gran error considerar que Cuvier, pese a sus diferencias con el antiguo intendente del Jardín du Roi (Corsi, 2001, p. 16), haya pretendido restaurar esa concepción meramente descriptiva y taxonómica de la historia natural. Decir que para Cuvier la ciencia se resumía a «un catálogo de hechos» (Grimoult, 1998, p. 52) constituye una terrible inexactitud.

En realidad, en lo atinente a la oposición entre Linneo y Buffon, Cuvier parecía procurar algo así como una síntesis superadora. Una posición que preservase el rigor descriptivo y clasificatorio de la historia natural linneana sin renunciar a las pretensiones teóricas de Buffon. Pero claro: sometiendo siempre el impulso generalizador buffoniano al permanente control de los hechos (cfr. Coleman, 1964, p. 24). Lector de Kant, Cuvier pudo muy bien haber pensado lo siguiente: los detalles linneanos sin conjeturas buffonianas serían ciegos, pero estas sin aquellos serían vacías y podrían llevarnos a cualquier parte. Por eso, según leemos en el «Prospectus» del Dictionnaire des Sciences Naturelles, los naturalistas siempre oscilan entre Buffon y Linneo buscando en uno lo que al otro le falta (Cuvier, 1816, pp. vi-vii, apud Coleman, 1964, p. 24-25).

Lo cierto, de todos modos, es que el concepto cuvieriano de 'historia natural' no puede ser entendido como opuesto a filosofia natural; sino que debe ser entendido en términos de la distinción entre physique générale y physique particulière (Cuvier, 1817, pp. 2-3). Según lo consignaba el artículo sobre «Historia» de la Encyclopédie, la historia natural [«improprement dite histoire»] debía ser considerada «una parte esencial de la física» (Diderot \& D’Alembert, 1999 [1765]); y así parecía entenderlo Cuvier (1798, p. 2) cuando caracterizaba a su disciplina como 'física particular'.

La física general era, desde su perspectiva, aquella parte de la física que consideraba «aisladamente las propiedades comunes a todos los cuerpos» (Cuvier, 1798 , p. 1); y la misma se componía de dos ramas: la dinámica y la química (Cuvier, 1817a, p. 2). La primera de estas ramas, nos decía Cuvier (1798, pp. 1- 
2), «trata de las leyes generales del movimiento y de su comunicación, de la fuerza que lleva a los cuerpos los unos sobre los otros, y que retienen sus moléculas en estado de adherencia o de cohesión». La segunda, mientras tanto, «expone las leyes según las cuales las moléculas elementales de los cuerpos actúan las unas sobre las otras a corta distancia, etc.» (Cuvier, 1798, p. 2).

Por su parte, la física particular o historia natural procuraba «aplicar a los numerosos y variados seres que existen en la naturaleza, las leyes reconocidas por los diferentes ramos de la física general, con el fin de explicar los fenómenos que cada uno de esos seres presenta» (Cuvier, 1817a, p. 3-4); y, en ese sentido, agregaba Cuvier (1817a, p. 4), hasta la astronomía debía ser considerada como un capítulo de la historia natural. Aunque, al estar totalmente iluminada y regida por las leyes de ese capítulo de la dinámica que es la mecánica, la astronomía podía emplear «métodos muy diferentes de aquellos que permite la historia natural ordinaria» y por eso no era «cultivada por las mismas personas» (Cuvier, 1817a, p. 4). Así, la historia natural, en el sentido usual y más restricto del término, se restringía, de hecho, al estudio de esos objetos que «no admiten cálculos rigurosos, ni medidas precisas en todas sus partes» y eso incluía a «los cuerpos brutos, llamados minerales, y los diversos tipos de seres vivientes» (Cuvier, 1817a, p. 4).

Pero, sobre todo en el caso del estudio de estos últimos, a la inviabilidad de los cálculos rigurosos, Cuvier (1817a, p. 5) también añadía la dificultad o incluso la imposibilidad de seguir procedimientos experimentales. Por eso, ese conocimiento de los cuerpos brutos y de los seres organizados propio de la historia natural no podría ser conquistado, por lo menos durante mucho tiempo y en la mayoría de sus partes, ni basándonos preponderantemente en el cálculo, como ocurre con la dinámica, ni tampoco basándonos casi exclusivamente en experimentos como ocurre con la química. El método disponible para la fisica particular no podría ser otro, por lo tanto, que el método de la observación (Cuvier, 1817a, p. 5; ver: Coleman 1964 p. 30).

Con todo, el reconocimiento de esa limitación en lo atinente al rigor matemático y experimental que era esperable en este último campo de estudios no implicaba renunciar a un ideal de conocimiento explicativo y nomotético $\mathrm{Cu}$ vier, 1817a, p. 6); y esto, según Cuvier, se debía a dos razones. La primera de estas razones tiene que ver con el hecho de que en los cuerpos analizados por la historia natural era posible observar los efectos de «las leyes del movimiento», de las «atracciones químicas», así como «de todas las otras causas analizadas por la física general» (Cuvier, 1817a, p. 4); y, por eso, era menester mantener el objetivo de establecer de qué modo tales leyes, tales causas y tales atracciones, regulaban la constitución y el funcionamiento de esos seres (Cuvier, 1817a, p. 
6). Pero, según Cuvier (1817a, p. 6), además de procurar la posible aplicación de las leyes de la dinámica y de la química a la explicación de la constitución de los diferentes cuerpos, brutos u organizados (Daudin, 1926b, p. 61), la historia natural debía también procurar sus leyes específicas; aun cuando no pudiese contar, ni con el cálculo, ni con el experimento para cumplir con esa tarea (Coleman, 1964, p. 30; Appel, 1987, p. 47).

Para obtener esas leyes, «el proceso más fecundo», nos dice Cuvier (1817a, p. 7) «es el de la comparación»; y el mismo consiste en «observar sucesivamente el mismo cuerpo en las diferentes posiciones que la naturaleza lo pone, o en comparar entre sí a diferentes cuerpos hasta que se haya conseguido reconocer relaciones constantes entre su estructura y los fenómenos que en ellos se manifiestan». Tales cuerpos, explicaba Cuvier (1817a, p. 7), «son especies de experimentos preparados por la naturaleza que agrega o suprime a cada uno de ellos diferentes partes, del mismo modo en que desearíamos hacerlo en nuestros laboratorios, mostrándonos ella misma los resultados de estas adiciones o supresiones».

Si Cuvier hubiese llegado a leer la Lógica de Mill (1959 [1843], p. 391), publicada, al fin y al cabo, sólo once años después de su muerte, hubiese podido decir que el método de la diferencia podía tanto aplicarse en el dominio de la investigación experimental cuanto en el dominio de la investigación comparativa: en un caso somos nosotros que introducimos la diferencia, en el otro es la naturaleza que la produce ( $c f r$. Bernard, 1985 [1865], p. 181; Schaffner, 1993, p. 145). Para Cuvier, dice Jacob (1973, p. 201), «la naturaleza experimentaba para el naturalista» y esos experimentos eran tanto o más confiables que aquellos hechos en el laboratorio. Por su mediación, pensaba Cuvier (1817a, p. 7), la historia natural podía establecer leyes «como aquellas que han sido determinadas por las ciencias generales».

No había, por eso, ninguna razón para pensar que nunca surgiría un Newton de la historia natural (Cuvier, 1992 [1812], p. 47); y no falta quien piense que el propio Cuvier aspiraba a ser considerado como tal (cfr. Pellegrin, 1992, p. 29). Pero, sea como sea, lo cierto es que, según Cuvier (1817a, p. 7), «la conexión de esa leyes de observación con las leyes generales (...) complementaría el sistema de las ciencias naturales mostrando en todas sus partes la influencia mutua de todos los seres. Siendo a eso que deben tender los esfuerzos de todos aquellos que cultivan la ciencia». El mundo de este naturalista era, como afirma Coleman (1964 p. 29), una máquina; y la historia natural debía contribuir a que conociésemos no sólo el catálogo de sus piezas, sino también parte de los principios generales de su funcionamiento.

Es cierto, en la perspectiva de Cuvier, la búsqueda de esas leyes de observación propias de la física particular, constituía una empresa colectiva y co- 
operativa que cabría definir, en ese sentido preciso, como baconeana. Es decir: una empresa que no pudiendo quedar librada a las intuiciones abstractas de unos pocos galileos, debía depender del trabajo mancomunado y coordinado, en lo posible desde París y por él mismo, el Napoleón de la historia natural, de naturalistas de todos los países civilizados que irían acumulando, no sólo hechos, sino también generalizaciones observacionales que luego convergerían con las leyes de la física general en la constitución de un cuadro unitario del mundo (cfr. Cuvier: 1810, p. 301 y s.; 1861a, p. 278 y ss.; $c f r$. Daudin, 1926b, p. 69; Pellegrin, 1992, p. 9). Y es en el horizonte de ese camino baconiano hacia objetivos newtonianos que debemos entender el proyecto cuvieriano para la anatomía comparada.

\section{LA ANATOMÍA COMPARADA}

Hoy, en el espacio de inteligibilidad inaugurado por Darwin, leemos la anatomía comparada como Carl Gegenbaur nos enseñó a hacerlo (López Piñero, 1992, pp. 43-48); es decir: como un conjunto de evidencias que prestan testimonio de la genealogía de los seres vivos. Por eso tendemos a considerarla como una disciplina perteneciente al campo de la biología evolutiva. Pero esto puede llevarnos a un engaño cuando intentamos comprender el significado que esa disciplina tenía para los predecesores de Darwin y, sobre todo, para Cuvier. Donde no se reconoce la comunidad de descendencia, los datos de la anatomía comparada no pueden tener ningún significado genealógico.

Eso no quiere decir, sin embargo, que las categorías taxonómicas hayan sido para Cuvier, como ocurría en la taxinomia clásica, «meras regiones de semejanzas, agrupamientos de analogías que se podrían establecer, bien arbitrariamente a partir de un sistema de signos, bien siguiendo la configuración general de las plantas y los animales» (Foucault, 1994 [1969], p. 33). En el proyecto cuvieriano, las categorías taxonómicas no son otra cosa que tipos de organización (Appel, 1987, p. 45; Bowler, 1996, p. 45); y así lo expresa el título de la más importante obra sistemática de Cuvier (1817a), Le règne animal distribué d'après son organisation, pour servir de base a l'histoire naturelle des animaux et de introduction a l'anatomie comparée.

En el contexto de esa obra, nos explica Foucault (1994 [1969], p. 33), «pertenecer a un género, a un orden, a una clase no significa tener en común con otras especies determinados caracteres menos numerosos que los caracteres específicos, no significa tener un carácter genérico o un carácter de clase, sino poseer una organización precisa». Por eso, desde esa perspectiva, la ads- 
cripción de una forma viviente a una categoría taxonómica, sin implicar nada semejante a una hipótesis sobre su genealogía, era lo mismo que formular una caracterización de su fisiología, era adjudicarle un modo de organización ( $c f r$. Pellegrin, 1992, p. 20). Los tipos cuvierianos son tipos fisiológicos: los mismos no son otra cosa que los modos fundamentales de la economía animal.

Pero lo relevante, lo que realmente debe importarnos aquí, es entender porqué era la anatomía comparada la disciplina que estaba llamada a guiar esa taxonomía fisiológica. Para ello debemos tener presente que para Cuvier la comparación era un método que podía sustituir a la experimentación y al cálculo allí donde la complejidad de los fenómenos analizados impedía la aplicación de estos últimos procedimientos; y ese era el caso de los seres organizados: la comparación de las diferentes conformaciones de los seres vivos era el único modo posible de acceder a sus leyes específicas de organización y funcionamiento.

Así, cuando leemos la carta a Mertrud que sirve como presentación de las Leçons d'anatomie comparée nos encontramos que allí lo que está en juego es el delineamiento de un método que le permita superar al fisiólogo el obstáculo que significa la inextricable complejidad de los seres vivos (Cuvier, 1805 , p. III y ss.) La fisiología, le explicaba Cuvier (1805, p. iv) a Mertrud, no sólo está en cierta desventaja frente a las ciencias de cálculo como la dinámica; sino que incluso se encuentra en desventaja frente a ciencias como la química y la física experimental. Estas, operan sobre substancias no orgánicas que pueden ser metódicamente aisladas y combinadas sucesivamente entre ellas; permitiendo así «reducir a una simplicidad casi indefinida los problemas que ellas se plantean». La fisiología, en cambio, no tiene tanta suerte: «todas las partes de un cuerpo vivo están conectadas; las mismas no pueden actuar sino es en conjunto: querer separar una de la masa, es conducirla al orden de las sustancias muertas, es cambiar su esencia» (Cuvier, 1805, p. v) ${ }^{3}$.

«Las máquinas que constituyen el objeto de nuestras investigaciones», continúa Cuvier $(1805$, p. v), «no pueden ser desmontadas sin ser destruidas». Por eso, «no podemos conocer lo que resultaría de la ausencia de uno o de varios de sus engranajes, $y$, por consecuencia, no podríamos saber cuál es la parte que cada uno de esos engranajes toma en el efecto total». Es decir: no sabríamos cuál es la función de ese elemento en la constitución y el funcionamiento de lo que Cuvier (1805, p. 19) mismo llamaba «máquina animal»

3 Ese mismo pasaje de la carta a Mertrud es citado por Claude Bernard cuando, en su Introducción al Estudio de la Medicina Experimental de 1865, reseña los argumentos contrarios a la posibilidad de desarrollar una fisiología experimental. Cuvier, nos dice Bernard, «piensa que la fisiología debe ser una ciencia de observación y de deducción anatómica», p. 100. 
(cfr. Appel, 1987, p. 47). Pero afortunadamente es la propia naturaleza la que, ofreciéndose a sí misma un genuino laboratorio (Lenoir, 1982, p. 63), nos suministra, como decía Cuvier (1805, p. v), «los medios de suplir esa imposibilidad de hacer experimentos sobre los cuerpos vivos». En efecto, explorando y saturando el espacio de lo biológicamente posible, la naturaleza, según leemos en la carta a Mertrud:

«nos presenta en las diferentes clases de animales casi todas las combinaciones posibles de órganos; ella nos los muestra reunidos, dos a dos, tres a tres, y en todas las proporciones; no hay, por así decir, ningún órgano del cual ella no haya privado a alguna clase o género; y basta examinar los efectos producidos por esas reuniones y privaciones, para deducir conclusiones muy verosímiles sobre la naturaleza y el uso de cada órgano y de cada clase de órgano» (Cuvier, 1805, pp. v y vi) ${ }^{4}$.

Como vemos, para Cuvier la anatomía comparada era un método, el método, para producir conocimiento fisiológico (Daudin, 1927, p. 15); es decir: conocimiento de la economía animal (Balan, 1979, p. 73); y por economía animal, Cuvier (1805, p. 1), al igual que todos sus contemporáneos, no entendía otra cosa que aquel orden intra-orgánico que él llamaba organización y cuya vigencia coincidía con la duración de ese torbellino que era la vida misma. Roto ese orden, el viviente se desorganizaba y sus elementos se dispersaban en el espacio de las substancias muertas (Cuvier: 1798, p. 6; 1805, p. 2; ;1810, p. 201, 1817a, p. 12). Para Cuvier (1805, p. 2), como para Bichat (1994a [1800], p. 57) vivir es resistir a la muerte; y el objeto de la fisiología consiste en saber como se ejerce y se organiza esa resistencia (cfr. Bernard, 1878, pp. 28-29).

En suma: para Cuvier la historia natural de los cuerpos vivos es preeminentemente fisiología; y es en ese sentido que puede decirse que su anatomía comparada parecería tener más que ver con el dominio de lo que hoy llamaríamos biología funcional que con el dominio de lo que hoy llamaríamos biología evolutiva o historia natural en la acepción actual de la palabra. Examinando las partes del cuerpo como un anatomista, Cuvier quería, antes que nada, comprenderlas como un fisiólogo (Coleman, 1985, pp. 37-38); y eso se verifica cuando nos asomamos al corpus cuvieriano: los textos que lo componen son los textos de un fisiólogo. Lo que allí leemos son análisis de los diferentes órganos y partes de un viviente que aluden, ora a su papel en el funcio-

4 Cuvier, nos dice E.S.Russell (1916), p. 39, no tenía una teoría específica sobre la variedad de las formas orgánicas; pero, a falta de una explicación biológica para ese hecho, sí contaba con una estupenda justificación epistemológica para el mismo. 
namiento de la máquina animal, ora al modo por el cual esa función es cumplida (Daudin, 1926b, pp. 62-63).

La anatomía comparada sería, en este sentido, la disciplina que mejor permitiría cumplir con esa máxima que más tarde Comte (1838, p. 237) propondría como formulación del objetivo cognitivo de toda la biología: «dado el órgano o la modificación del órgano encontrar la función o el acto, y recíprocamente»; y aunque nunca formuló una definición explícita de función análoga, por ejemplo, a la clara definición de Historia Natural que hemos analizado más arriba, Cuvier nunca dejó de ser claro respecto de lo que entendía por ese concepto que, como Coleman (1985, p. 241) dice, constituye el objeto privilegiado de la fisiología.

Para Cuvier, una función era, en primer lugar, toda operación del organismo que resultase necesaria, ora para la manutención de la vida de ese mismo organismo, ora para su reproducción ( $c f r$. Cuvier, 1805, pp. 18-19; 1817a p. 36). Siendo en ese sentido de la palabra función que Cuvier (1817a, p. 36) distinguía entre las 'funciones vitales' y las 'funciones animales'. Las primeras, según se las enumera en las Leçons, son todas las que tienen que ver con la nutrición del organismo: digestión, absorción, circulación, respiración y excreciones; y las mismas, siendo comunes a plantas y animales, cumplen con

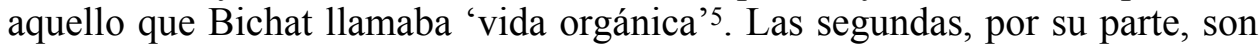
la sensibilidad y el movimiento voluntario; siendo ellas las encargadas de cumplir con aquello que Bichat (1994a [1800] p. 62) llamaba de 'vida animal' (Russell, 1916, p. 32).

Así, en un sentido secundario, derivado, podremos hablar también de la función de un órgano particular entendiendo por ello el papel desempeñado por la actividad de ese órgano en el cumplimiento o ejercicio de tales operaciones ( $c f r$. Cuvier, 1805, p. v, p. 19) ${ }^{6}$. Siendo a esa misma noción fisiológica

5 En las Lecciones de anatomía comparada, Cuvier, p. 19, nos dice que la generación es una función de «tercer orden»; es decir: una función que, en lugar de estar involucrada en la manutención del organismo individual, esta «destinada a reemplazar los organismos que perecen por organismos nuevos y a mantener la existencia de cada especie»; y esto es también un eco de Bichat (1994a [1800] p. 62): para el autor de las Recherches physiologiques, la generación no forma parte ni de la vida orgánica ni tampoco, claro, de la vida animal: estas vidas, según leemos en esa obra, tienen que ver con el individuo; la generación, mientras tanto, es una función que sólo concierne a la especie. En el Reino Animal, sin embargo, Cuvier (1817a, p. 36) preferirá incluir a la generación dentro del conjunto de las funciones vitales.

6 Algo muy próximo a esa distinción entre dos sentidos o usos del término función, de hecho presente en todo libro de fisiología, aparece también en los escritos de Galeno bajo la forma de la oposición entre función y utilidad. El efecto total o la contribución global de un 
de función, y no a nada semejante con la idea darwiniana de adaptación, que Cuvier (1805, p. vi) aludía cuando decía que la anatomía comparada nos permitía conocer la función de un órgano y de cada una de sus partes.

Es cierto, la aproximación entre las expresiones 'uso [usage] de un órgano' y 'función [fonction] de un órgano' que encontramos en la carta a Mertrud puede darnos la impresión de que Cuvier (1805, p. vi) esté aludiendo a alguna cosa semejante a aquello que Bock y Wahlert (1998, p. 131) describen como el rol biológico de una estructura. Pero el hecho de que en esas mismas páginas sólo se aluda a la comparación entre estructuras anatómicas como siendo el único «método de razonar en fisiología» (Cuvier, 1805, p. vi), y no se diga nada del análisis de las condiciones de vida del organismo, refuerza la impresión de que esas nociones de usage y fonction están siendo usadas en el mismo sentido en que luego podría usarlas, según veremos más abajo, el propio Claude Bernard. Sólo que para este, claro, el método a seguir para establecer ese valor funcional no era la comparación anatómica sino la experimentación.

La noción de rol biológico, mientras tanto, tiene que ver con la acción o el uso de un rasgo orgánico en el curso de la historia de vida de su portador (Bock \& Wahlert, 1998, p. 130); y su conocimiento exige algo que no puede hacerse en el gabinete del anatomista. «La observación del organismo viviendo naturalmente en su ambiente», nos dicen Bock y Wahlert (1998, p. 131), «es esencial a la descripción de un rol biológico». Por eso, mientras «la función de un rasgo puede ser estudiada y descripta independientemente del ambiente natural de un organismo, como de hecho se lo hace en la mayoría de los estudios de anatomía funcional» (Bock \& Wahlert, 1998, p. 125), el rol biológico «no puede ser determinado por observaciones hechas en el laboratorio o bajo otras condiciones artificiales» (Bock \& Wahlert, 1998, p. 132) y debe ser estudiado en campo.

En los estudios de anatomía funcional, el experimento o la simple comparación con formas emparentadas a la que Cuvier recurría, pueden servir para establecer si las extremidades de un cuadrúpedo extinto tenían o no una función locomotora; pero difícilmente ese estudio sería suficiente para indicarme a que rol biológico obedecía el tamaño de esas extremidades: el mismo podría estar vinculado con la fuga de predadores, con el desplazamiento en una zona pantanosa, con el fin de conseguir comida o con cualquier otra circunstancia de la cual sólo podríamos tomar conocimiento observando el modo de vida de ese

conjunto de órganos al funcionamiento de un organismo constituye una función, el papel de cada parte anatómica en el cumplimento de esa función es la utilidad de la misma. Y, como Galeno subraya, es necesario primero identificar la función en cuyo cumplimento el órgano está implicado para luego determinar la utilidad de sus partes (Galien, 1994, p. 15 y p. 317). 
cuadrúpedo. Por eso, nos dicen Bock y Wahlert (1998, p. 132), la «determinación de roles biológicos es especialmente difícil en formas fósiles o en organismos recientes cuya historia de vida no es conocida». Pero eso, en nada afectaba a la mirada fisiológica que Cuvier dirigía a los seres extintos.

\section{EL CONCEPTO DE CONDICIÓN DE EXISTENCIA}

Es en clave fisiológica, incluso, que debemos entender la célebre formulación del Principio de las Condiciones de Existencia - «vulgarmente denominado principio de las causas finales»- que aparece en Le Règne Animal $(\mathrm{Cu}-$ vier, 1817a, p. 6). El mismo, es cierto, dice así: «como nada puede existir si no reúne las condiciones que tornan su existencia posible, las diferentes partes de cada ser deben estar coordinadas de manera tal que posibiliten el ser total, no solamente en sí mismo, sino también con relación a aquellos seres que lo circundan». Pero, como nos dice Russell en Form and Function (1916, p. 34), pese a esa alusión al entorno de los organismos, que los comentaristas de Cuvier suelen resaltar ( $c f r$. , por ejemplo, Boutroux, 1949, p. 89; Daudin, 1927, p. 19; Gohau, 1974, p. 90; Appel, 1987 p. 4; López Piñero, 1992 p. 23; Grimoult, 1998 p. 15; Bowler, 1998, p. 192), el ambiente [environment], no tiene un papel relevante en su pensamiento.

Por condiciones de existencia, Russell tiene razón (1916, p. 34), Cuvier «entendía algo muy diferente de lo que hoy es comúnmente entendido». Atento al hecho de que todas las partes de un cuerpo organizado ejercen «una acción recíproca las unas sobre las otras y concurren a un fin común que es la manutención de las vida» (Cuvier, 1798 p. 5), nuestro autor consideraba que «la verdadera condición de existencia de un ser vivo, y parte de su definición esencial, es que sus partes trabajen juntas para el bien del todo» (Russell 1916 p. 34). Por eso, sus indagaciones se centraban, casi exclusivamente, «sobre las adaptaciones de la función y el órgano dentro de la criatura viviente» (Russell 1916, p. 34). Cuvier, en contra de lo que Bowler (1998, p. 192), Gould (2003, p. 16) y otros han dicho, no era tributario de una perspectiva adaptacionista o utilitarista.

Para él, en realidad, las condiciones de existencia tienen que ver, antes que nada, con la condición de posibilidad de un ser vivo considerado en sí mismo como un todo coherente y armónico (léase: organizado); y esto se hace evidente cuando, en un pequeño escrito sobre las analogías zoologicas (cfr. Coleman, 1964, pp 189-190), la idea de condiciones de existencia aparece vinculada a la idea de no contradicción: «todas las combinaciones que son no contradictorias 
son posibles; en otras palabras, todo aquello que tiene una condición de existencia, cuyas partes cooperan en una acción común, es posible»(Cuvier apud Coleman, 1964, pp. 189). Un organismo, en síntesis, es un sistema cuya primera y fundamental condición de existencia es su coherencia interna.

Pienso, por eso, que E.S. Russell (1948, p. 286n) tenía razón cuando decía que Darwin había desvirtuado la noción cuvieriana de condiciones de existencia usándola como equivalente a condiciones del ambiente. De hecho, en la única referencia que en On the Origin of Species se hace al principio de las condiciones de existencia formulado por Cuvier, Darwin (cfr. 1859, p. 206) «usó la expresión conditions of existence para significar las condiciones ambientales [environmental] y consideró la ley de las condiciones de existencia como la ley de la adaptación al ambiente [environment]» (Russell, 1916, p. 239). Para Darwin $(1859$, p. 127), en resumen, las condiciones de existencia se homologan a las conditions of life (siendo esa la expresión que de hecho él usa); y las mismas tienen que ver, no con las coordinación de las partes en la constitución del todo, sino más bien con las contingencias de la lucha por la supervivencia.

Es cierto: un desplazamiento semántico como el que Darwin hizo en relación al término condiciones de existencia no es algo infrecuente en la historia de una ciencia: los mismos, además, muchas veces encarnan y posibilitan desplazamientos conceptuales que acaban mostrándose progresivos o por lo menos fecundos 7 y este que nos ocupa podría ser un buen ejemplo de ello. Pero como historiadores de esa ciencia no podemos permitirnos que ese desplazamiento de Darwin condicione nuestra interpretación de Cuvier. Si insistimos en leer los textos de este por sobre el hombro de aquel, acentuaremos y sobrevaluaremos indebidamente sus referencias al entorno del viviente y minimizaremos sus referencias a la coherencia interna del organismo: perderemos de vista al Cuvier fisiólogo y en su lugar construiremos la imagen de un naturalista (otra vez: en el sentido actual de la palabra) preocupado en estudiar las relaciones del viviente con su entorno.

Parece, sin embargo, que la interpretación y, si se quiere, la reducción darwiniana del Principio de Condiciones de Existencia caló tan hondo en nuestro modo de considerar lo viviente que cuesta leer cualquier referencia a ese principio sin que nuestro espíritu no evoque la idea de un entorno mez-

7 Claude Bernard, sin ir más lejos, también hizo un uso no-cuvieriano de esa expresión: en sus textos las condiciones de existencia (de un fenómeno) no son otra cosa que las causas próximas que lo producen (cfr. Bernard, 1984 [1865], p. 123); y algo semejante encontramos en Von Baer (1973 [1873], p. 423) cuando, criticando los abusos de la perspectiva teleológica en fisiología, opone la búsqueda de propósitos a la búsqueda de condiciones de existencia de los fenómenos. 
quino y amenazador al cual el ser vivo debe adaptarse. Idea que, por lo demás, era ajena al pensamiento de Cuvier. La naturaleza para Cuvier estaba todavía dominada por una economía en donde cada ser vivo tenía una función a cumplir (Daudin, 1926b, p. 58; Conry, 1974, p. 363; Balan, 1979, p. 159; Coleman, 1985 , p. 38) y no un lugar a conquistar o a defender, como ocurre en el caso de Darwin (1859, p. 78; Limoges 1976 p. 77 y ss.)

Como Von Uexkull (1945, p. 175) alguna vez supo señalar, «en los seres vivos adultos distinguimos una doble conformidad a fin: de un lado, cada organismo está construido conforme un fin en sí mismo, y del otro, el organismo está adaptado conforme a fin a su entorno»; y una de las diferencias entre Darwin y la mayor parte de sus predecesores está en haber dejado en segundo plano esa conformidad a fin interna para dirigir nuestra intención hacía la adaptación del organismo a su ambiente. No es, claro, que esa adecuación haya sido negada por la biología pre-darwiniana; lo que ocurrió más bien es que la misma nunca fue problematizada: era dada por obvia. Darwin, en cambio, no sólo la rescató de ese discreto cono de sombra, sino que incluso la transformó en clave de la otra forma de adecuación; y ahí reside su gran diferencia con Cuvier (cfr. Caponi, 2003, p. 32).

En los últimos años, lo sabemos, ha sido muy citado aquel pasaje de Form and Function en el cual Russell (1916, p. 78) comenta el conflicto entre el funcionalismo de Cuvier y el formalismo de Etienne Geoffroy Saint-Hilaire, diciendo que «el contraste entre la actitud teleológica, con su insistencia en la prioridad de la función sobre la estructura, y la actitud morfológica, con su convencimiento de la prioridad de la estructura sobre la función, es uno de los más fundamentales de la biología» (por ejemplo, Ruse, 1983, p. 189; Amundson, 1998, p. 154; Gould, 2002, p. 329). Lo que, sin embargo, muchos parecen pasar por alto es que lo que Russell entendía por actitud teleológica no era el privilegio, darwiniano, del estudio de la adaptación del organismo al ambiente por sobre el análisis de su coherencia estructural; sino el privilegio, podríamos decir cuvieriano, del estudio de la unidad funcional del organismo por sobre el estudio de su pauta morfológica.

Russell, es verdad, habla de adaptación funcional, pero lo que él, crítico de Darwin, entiende por esto no es precisamente la adaptación darwiniana a las conditions of life, sino justamente la adecuación de una estructura a su función en la economía animal. En cierto sentido, Form and function es una reivindicación del organicismo funcionalista de Cuvier frente a ciertos aspectos de la biología darwiniana que Russell consideraba negativos ${ }^{8}$; y si ese

8 De hecho, en lo que atañe a la oposición por él colocada, y según se evidencia dos párrafos más abajo, Russell (1916, p. 78) pone a Darwin del lado de Geoffroy y no del lado de 
aspecto del libro de Russell hubiese sido considerado es posible que la imagen de Cuvier como un adaptacionista pre-darwiniano nunca hubiese cobrado tanta fuerza y difusión.

\section{EL KANTISMO DE CUVIER}

Ese error en la interpretación de Cuvier guarda, además, cierta estrecha solidaridad con otro error también bastante difundido y que es imprescindible evitar en pro de una cabal comprensión del programa cuvieriano: me refiero a la reducción o aproximación de Cuvier a Paley que podemos encontrar en autores como William Coleman (1964, p. 43; 1985, p. 38), Toby Appel (1987, p. 46), Michael Ruse (2000, p. 215) y Peter Bowler (1998, p. 192). Esa confusión, como sabemos, ha sido recientemente apuntada y criticada por Chris McClellan (2001, p. 7). Sin embargo, aún cuando McClellan (2001, p. 7) tenga razón al señalar que la posición de Cuvier no supone una teleología a la Paley, creo que se equivoca al no reconocer el lugar que la teleología interna a la Kant tiene, no sólo dentro del pensamiento de Cuvier, sino incluso dentro del pensamiento de Claude Bernard al cual su trabajo también alude.

Es que, como Russell (1916, p. 35) y Cassirer (1948, p. 161) oportunamente lo subrayaron, y pese a que Coleman (1964, p. 42) lo pasó por alto, Cuvier pensaba que el uso de nociones teleológicas en el estudio de los seres vivos no podía sino responder al esquema apuntado por Kant $(1991$, \$66) en la tercera crítica. Si Cuvier hubiese pensado que el argumento del diseño era un supuesto necesario o un soporte conveniente para su perspectiva funcionalista, habría podido citar en su favor la cuestión 28 de la Optica de Newton o el apartado 19 del Discurso de Metafísica de Leibniz. Pero, en lugar de eso, en las primeras páginas de sus Lecciones de Anatomía Comparada, leemos que, «según la expresión de Kant, la razón de ser de cada parte de un cuerpo vivo reside en el conjunto» (Cuvier, 1805, p. 6).

Esa es, precisamente, la idea expresada en ese primer corolario del Principio de las Condiciones de Existencia (Coleman, 1964, p. 67) denominado Principio de la Correlación de las Formas en los Seres Organizados que, según Russell

Cuvier (ver también la página 305); y esto no debe parecernos extraño: por lo menos en ese punto, Russell, como Peter Bowler (1996, p. 42) lo ha subrayado, adscribe a una tradición historiográfica según la cual «la vieja concepción idealista de 'relación' podría ser muy bien traducida por el concepto materialista de formas relacionadas por su descendencia de un ancestro común». 
(1916, p. 35), es la genuina piedra fundamental del proyecto cuvieriano: «todo ser organizado forma un conjunto, un sistema único y cerrado, en el cual todas las partes se corresponden mutuamente, y convergen a la misma acción definitiva por una reacción recíproca» (Cuvier, 1992 [1812], p. 97). Pierre Janet (1882, p. 64) no se equivocaba: adoptando el Principio de la Correlación de las Formas en los Seres Organizados, Cuvier hace suyo el concepto de producto organizado de la naturaleza que encontramos en la tercera crítica: «Un producto organizado de la naturaleza», nos dice allí Kant $(1991, \S 66)$ - un organismo, podemos leer nosotros-, «es aquél en que todo es fin, y recíprocamente, también medio»; es aquél en que «cada parte, así como existe sólo por todas las otras, es pensada también como existente para las otras y para el todo» (Kant, 1991, \$65).

Y no es irrelevante para nuestra discusión el hecho de que Cuvier haga suya una noción de organismo que es prácticamente idéntica a aquella que encontraremos en la Introducción al Estudio de la Medicina Experimental cuando Claude Bernard (1984 [1865], p. 137) nos diga que en los cuerpos organizados «todas las acciones parciales son solidarias y generadoras las unas de las otras». Es que, tanto el proyecto de Cuvier (1805, p. 46) cuanto el de Bernard (1878, p. 340) se centraban, como de hecho lo hace toda fisiología posible, en esta teleología intra-orgánica que Kant había considerado como inherente a la definición de ser organizado (Cassirer, 1948, p. 161). Kant había entrevisto que, sin la noción de organismo entendido como entidad auto-constituyente, nunca podría pasarse del dominio de la fisica tout court al dominio de esa fisica de lo viviente que hoy llamamos biología funcional (cfr: Keller, 2000, p. 106; Lebrun, 1993, p. 600; Marques, 1987, p. 192); y tanto Cuvier cuanto Bernard subscribieron y confirmaron esa presunción.

El fisiólogo, decía Bernard (1984 [1865], p. 137), no debe «olvidar jamás que el ser vivo forma un organismo y una individualidad» $\mathrm{y}$ «debe preocuparse por la armonía de ese conjunto al mismo tiempo en que intenta penetrar en su interior para comprender el mecanismo de cada una de sus partes». Por eso:

Mientras el físico o el químico pueden negar toda idea de causas finales en los hechos que observan; el fisiólogo es llevado a admitir una finalidad armónica y preestablecida en los cuerpos organizados cuyas acciones parciales son todas solidarias y generadoras las unas de las otras. Es necesario reconocer, por eso, que si se descompone el organismo viviente aislando las diferentes partes, es sólo para facilitar del análisis experimental, y no para concebir esas partes aisladamente. En efecto, cuando se quiere dar a una propiedad fisiológica su valor y su verdadera significación, siempre es necesario remitirse al conjunto y no sacar ninguna conclusión definitiva si no es en relación a sus efectos en relación a ese conjunto (Bernard, 1984 [1865], p. 137). 
Mas aún, según leemos en las Leçons sur les phénomènes de la vie communs aux animaux et aux végétaux (Bernard, 1878, p. 340), «el agrupamiento de los fenómenos vitales en funciones» - cuya relevancia en el programa de Cuvier analizamos más arriba - sería «expresión de ese pensamiento» según el cual «todo acto de un organismo vivo tiene su fin en el seno de ese organismo». Una función, nos dice en efecto Bernard, no es otra cosa que «una serie de actos o de fenómenos agrupados, armonizados, en vistas a un resultado determinado» (Bernard, 1878, p. 370); y, si bien, para la ejecución de dicha función concurren «las actividades de una multitud de elementos anatómicos», ella no puede ser reducida a la «suma brutal de las actividades elementales de células yuxtapuestas» (Bernard, 1878, p. 370). Lejos de eso, para individualizar una función, para que quepa describir un conjunto de actividades orgánicas como cumpliendo una función, debemos considerarlas como «armonizadas, concertadas, de manera a concurrir en un resultado común» (Bernard, 1878, p. 370).

Por eso, para Bernard y para Cuvier, al igual que para cualquier fisiólogo, la comprensión fisiológica de dicho acto se alcanza cuando se llega a conocer cual es el rol causal, o función, que el mismo tiene en la constitución y la preservación de ese organismo (cfr. Caponi, 2002, p. 67 y ss): sin perseguir ese objetivo cognitivo no hay fisiología o biología funcional posible. Y si la coincidencia en objetivos cognitivos nos importa más que la divergencia en estrategias metodológicas, tal vez podamos considerar a la fisiología de Claude Bernard como siendo el resultado de una reformulación en términos experimentales del programa de Cuvier.

\section{CONDICIONES DE POSIBILIDAD DE UNA ANATOMÍA DEDUCTIVA}

Es relevante apuntar, sin embargo, que, de ese organicismo común a toda fisiología posible, Cuvier extrae ciertas consecuencias extremas cuya comprensión nos ayuda a completar el cuadro de su programa para las ciencias de la vida. Para Cuvier, en efecto, «todos los órganos de un mismo animal forman un sistema único» en el cual todas las partes mantienen interacciones recíprocas; pero, de esa idea Cuvier infiere que no pueden existir modificaciones en ninguna de esas partes que no conduzcan a modificaciones análogas en todas las otras ( $c f r$. Cuvier, 1805, p. 46; 1810, p. 330). A Cuvier no le bastaba que los organismos sean considerados simplemente como un todo articulado: desde su perspectiva, como bien lo apuntaba Cassirer (1948, p. 162), los mismos debían ser considerados como un todo completamente articulado. Es 
decir: al no poder ser pensados como una «combinación fortuita de partes» los seres vivos debían ser entendidos y estudiados como constituyendo «una conexión cerrada, que lleva implícito un tipo peculiar de necesidad».

Así, desde esa perspectiva y como lo explica Cassirer (1948, p. 162), «una vez que hemos logrado conocer los tipos fundamentales de los seres vivos, no sólo sabemos lo que de hecho existe, sino también lo que puede y lo que no puede coexistir mutuamente». Siendo sobre esa presunción casi-leibniziana que Cuvier también fundaba su proyecto de paleontología demostrada según el orden geométrico (cfr. Papp, 1980, p. 59). El presupuesto de que la correlación de las formas orgánicas es estricta y rigurosa, al mismo tiempo en que torna impensable la trasformación de los tipos y las especies (Coleman, 1964, p. 171; Gould, 1984, p. 109), legitima también la pretensión de, por lo menos en principio, poder «reconocer un animal por un solo hueso, por una sola parte de hueso» (Cuvier, 1810, p. 330) e incluso también reconstruirlo con certeza geométrica a partir de ese único fragmento 9 :

«como la ecuación de una curva implica todas sus propiedades, y tomando separadamente cada propiedad para base de una ecuación particular se reencontraría la ecuación original y todas sus propiedades, al igual con las uñas, los omóplatos, los cóndilos, los fémures y todos los demás huesos, tomados separadamente, el que poseyera racionalmente las leyes de la economía orgánica podría reconstruir todo el animal» (Cuvier, 1992 [1812], p. 100).

Además, como consecuencia de esa genuina reconstrucción fisiológica de los fósiles, se tendría también conocimiento de su dieta y de su modo de vida: a partir de una uña o de un diente calcularíamos la forma de sus extremidades y de sus mandíbulas; y esto no sólo nos permitiría conocer la forma de los intestinos del animal sino también su tipo de alimentación. Siendo el conocimiento de esa dieta lo que nos llevaría finalmente al conocimiento de sus comportamientos e instintos (Cuvier, 1992 [1812], pp. 98-100). Es importante resaltar, sin embargo, que el hecho de que un organismo sea un sistema donde cada parte remite a otra, no significa que todas las partes posean la misma importancia.

Las características de un organismo no están simplemente correlacionadas: unas son preeminentes sobre las otras y, en ese sentido, las determinan $(\mathrm{Cu}-$ vier, 1798, p. 20). Según ese segundo corolario (Coleman, 1964, p. 67) del

9 Desde una perspectiva interna, la imposibilidad de pensar la transformación de tipos y especies puede ser considerada como una exigencia sistemática resultante de la aceptación de un presupuesto (el de la correlación estricta de las partes) que haría posible esa anatomía deductiva. 
Principio de las Condiciones de Existencia que Cuvier (1817a, pp. 10-11) denominó principe de la subordination des caractéres:

«Hay rasgos de conformación que excluyen a otros; los hay que, al contrario, se implican; por eso, cuando conocemos tal o cual rasgo en un ser, podemos calcular aquellos otros que coexisten con él, o aquellos que le son incompatibles. Las partes, las propiedades o los rasgos de conformación que poseen el mayor número de tales relaciones de incompatibilidad o de coexistencia con los otros, o en otros términos, que ejercen sobre el conjunto del ser, la influencia más marcada, son aquellos que llamamos caracteres importantes, los caracteres dominadores, los otros son los caracteres subordinados, habiéndolos en diferentes grados».

Y para Cuvier los rasgos que definían las características fisiológicas más generales de un organismo eran dominadores sobre aquellos que definían el modo por el cual un organismo se insertaba en la economía natural. Para $\mathrm{Cu}-$ vier, hubiese podido decir Ameghino (1915 [1884], p. 145), los caracteres de organización eran siempre más importantes que los de adaptación. Así, y según leemos en Le Règne Animal (Cuvier, 1817a, pp. 70-71), «es la respiración moderada de los mamíferos la que en general les dispone a marchar sobre la tierra con fuerza y de una manera continua»; y es en virtud de esta misma necesidad, y no por la mediación de alguno proceso lamarckiano o darwiniano de adaptación, que «un animal que no puede digerir otra cosa que carne, debe, bajo pena de destrucción de su especie, tener la facultad de percibir su presa, de perseguirla, de capturarla, de vencerla, de despedazarla». Él necesita, por eso y de manera imperiosa, dice Cuvier (1805, p. 55), «de una visión aguda, de un olfato delicado, de una carrera rápida, y de fuerza en las patas y en las mandíbulas».

Sin desentenderse definitivamente de la preocupación por eso que hoy, darwinianamente, llamamos de adaptación, Cuvier pensaba que para que un organismo se pueda adaptar a las exigencias de su ambiente en un sentido más o menos próximo al darwiniano, él mismo debía ser antes una estructura organizacionalmente posible; $y$, desde esa perspectiva, las estructuras anatómicas que definen el modo por el cual un animal se vincula a su entorno y a sus fuentes de alimento, son un corolario de su organización interna (Cuvier, 1817a, p. 69). Gran parte de lo que hoy llamaríamos a estrategias o estructuras adaptativas eran, para Cuvier $(1805$, p. 57), la resultante necesaria de ciertas leyes de coexistencia que rigen la fisiología de los organismos, y no una simple respuesta a las exigencias del ambiente: «una condición de la existencia de todo animal», decía Cuvier (1805, p. 51), «es que sus necesidades sean proporcionales a las facultades que él tiene para satisfacerlas». 
Para Cuvier, es cierto, un organismo es un sistema cuya armonía o coherencia interna, su condición de existencia, solamente puede ser percibida y comprendida considerando su inserción en el entorno; pero su modo de insertarse en este entorno no es independiente de su propia organización interna. Por el contrario: esa inserción es consecuencia, y no causa, de esa organización ( $c f r$. Nordenskiöld, 1949, p. 383; Gohau, 1974, p. 90; Le Guyader, 1988, p. 114). No es como respuesta a un desafío del ambiente que un predador deviene un animal rápido y astuto; sino en virtud de su propia fisiología de carnívoro (Cuvier, 1992, p. 98). Así, entre las tesis de Lamarck que más parecían irritarlo estaba la presunción de que no fuesen «la naturaleza y la forma de las partes» de un tipo de organismo «las que dan lugar a los hábitos y a las facultades»; sino que, por el contrario, este pensase que eran «los hábitos» y «la manera de vivir» los que hacían «nacer los órganos»(Cuvier, 1861b, p. 99).

Además, es precisamente esa preeminencia de las coerciones organizacionales sobre los factores adaptativos lo que explica el hecho de que Cuvier haya confiado en la posibilidad y en la legitimidad de reconstrucciones paleontológicas que no se apoyaban en ningún putativo conocimiento del ambiente en los cuales los seres en estudio habrían vivido. Cuvier carecía, en efecto, de cualquier cosa remotamente semejante a una paleoecología y no pretendía, ni quería, llenar ese vacío con conjeturas y especulaciones. Pero aun así, creía que sus reconstrucciones de fósiles eran viables y justificables a partir de las complejas leyes que regían la correlación y la subordinación de las partes. O como lo decía Littré ([1834] 1997, p. 152), cuando aún era un lector pre-darwiniano de Cuvier: «todo está en la organización de los seres animados; una parte determina otra parte; una función determina otra función».

La idea darwiniana de que la estructura de cada ser orgánico está indisolublemente relacionada con la estructura «de todos los otros seres orgánicos con los cuales entra en competición por comida o residencia, o de los cuales tiene que escapar o a los cuales tiene que hacer presa» (Darwin, 1859, p. 77), no es una tesis cuvieriana. Todo lo contrario: más allá de lo que pueda sugerir una lectura aislada de ciertos pasajes de Cuvier, la aceptación de esa tesis darwiniana anula la pretensión de deducir la estructura de un organismo a partir del conocimiento de sólo un fragmento o una parte importante del mismo: la idea de que la estructura del organismo obedezca a las contingencias del ambiente desbarata, y desbarató, el proyecto cuvieriano. 


\section{TEMAS CUVIERIANOS vs. TEMAS DARWINIANOS}

Por otra parte, aunque en cierto sentido Cuvier (1992 [1812] p. 98) haya llegado a sugerir que hasta aquellas características más particulares de un carnívoro que obedecían «al tamaño, a la especie y al hábitat de la presa para la cual el animal está dispuesto», se encontraban cifradas en la forma de cada una de sus partes, sus análisis nunca se demoraron en la tentativa de establecer correlaciones específicas entre presa y predador. En teoría, el programa cuvieriano contemplaba e implicaba la posibilidad de inferir la identidad de la presa partiendo de la fisiología del predador; pero lo cierto, sin embargo, es que Cuvier nunca parecía muy interesado en llevar sus razonamientos hasta ese nivel de precisión: su interés se restringía al plano morfológico y funcional.

De la organización se llegaba, como máximo, hasta la dieta: nunca hasta la presa que la proveía y menos aún al modo por el cual la misma era capturada. Los trabajos de Cuvier, como ya lo dijimos, siempre fueron los trabajos de un fisiólogo; y poco en ellos nos recuerda a los trabajos de un naturalista en el sentido actual de la palabra.

Así, en las Mémoires pour servir a l'histoire et à l'anatomie des mollusques, la tinta que pulpos, calamares y jibias expelen «ante la menor apariencia de peligro» es apuntada como una particularité remarquable de los cefalópodos (Cuvier 1817b p. 4); pero la referencia que se hace a ese posible rol biológico es superficial, lateral. Cuvier (1817b p. 1) alude a la cuestión en un primer parágrafo donde se enumeran algunas rarezas y singularidades de estos animales y allí nos dice que la expulsión de tinta constituye su «principal medio de defensa». Luego, retomando brevemente la cuestión, acepta la posibilidad de que esa tinta les sirva también a los cefalópodos para esconderse no solamente de sus posibles agresores sino también de sus eventuales presas.

Determinar hasta dónde y en qué casos eso es así no parece importarle mucho a Cuvier: «¿todos los cefalópodos — pulpos, calamares y jibias - usan del mismo modo y en las mismas ocasiones ese recurso?», es una pregunta que no parecería digna de ser formulada. Así, aún citando las observaciones de Aristóteles sobre los cefalópodos, nuestro autor ni siquiera menciona el hecho de que el estagirita considere que solamente la jibia usa su tinta para esconderse. La expulsión de tinta por parte del pulpo y el calamar, según leemos en la Historia de los Animales, sería un efecto del miedo y no un recurso protector; y Aristóteles no se apoya para decir esto en ninguna especulación psicológica, sino en un análisis del modo en que la jibia se comportaría una vez que la tinta salió de su cuerpo (H.A.621b, p. 519 de nuestra edición). Este animal, a diferencia del pulpo y del calamar, según Aristóteles dice, retornaría 
hacia la mancha de tinta aprovechándola como escondite. Y claro que no se trata aquí de saber quién tenía razón; sino de percibir cómo la perspectiva de Cuvier es indiferente a un tema que daría mucho para discutir.

Es significativo, además, que el joven naturalista supernumerario del HMS Beagle ya se haya mostrado más atento a este tipo de cuestiones que Cuvier. En el primer capítulo de su Voyage of the Beagle, Darwin (1911 [1839], p. 18) dice haber dedicado largas horas de su estancia en Cabo Verde al estudio del comportamiento de los pulpos y su conclusión es que, por lo menos esos pulpos, expulsan su tinta siempre que realizan traslaciones rápidas. Como vemos, su interpretación de ese comportamiento es diferente de la de Aristóteles y sería oficio de un naturalista, en el sentido que hoy damos al término, el determinar si uno u otro tienen razón, si ambos están equivocados o si los pulpos del Egeo se comportan de un modo diferente que los de la Isla de Santiago. Todas estas menudencias que no parecían preocuparle mucho a Cuvier.

Para este, sin duda, tanto la naturaleza y la composición del líquido segregado (Cuvier, 1817b, pp. 4-5), como la individualización y la descripción del órgano que lo produce y lo contiene (Cuvier, 1817b, p. 31) eran cuestiones mucho más importantes. Asuntos todos que, por otra parte, se pueden estudiar lejos de la playa: sobre el frío mármol de la mesa de disección, en Paris. Pero esto es comprensible: lo que para Cuvier (1817b, p. 42) está en juego es la caracterización de la organización de los cefalópodos: sus condiciones de existencia y no sus condiciones de vida; la función de sus partes y no su rol biológico.

Sin ser un biólogo de laboratorio, Cuvier era un biólogo de museo. Para él, la labor de los naturalistas viajeros era importante no en virtud del conocimiento que estos podían obtener respecto del modo de vida de los diferentes tipos de organismos en sus hábitats naturales, sino en virtud de los especímenes que podían enviar al museo para ser disecados, catalogados y analizados en cuanto que variaciones dentro de los tipos de organización fisiológicas conocidos ( $c f r$. Cuvier, 1861a, p. 279 y ss.; también 1978, p. 59 y ss.); y esto vale tanto para los especímenes de organismos actualmente existente como para las osamentas de organismos extintos. Siendo en ese contexto, por otra parte, donde se puede apuntar que existen diferencias anatómicas entre las distintas especies de pulpo sin intentar vincular esas diferencias con el modo de vida de estos animales; $y$, sobre todo, sin intentar vincularlas con los otros seres vivos que los rodean (Cuvier, 1817b, p. 7).

En la perspectiva cuvieriana, la variabilidad de una estructura dentro de un determinado tipo de organismo es inversamente proporcional a su importancia organizacional. Cuanto menos necesaria en términos fisiológicos sea una estructura, cuanto menos esencial ella sea para la cohesión y funcionamiento del todo, 
menos interés la misma habrá de despertar. Independientemente de cualquier posible consideración respecto de algo semejante a la utilidad adaptativa de una característica, su relevancia para la anatomía comparada será directamente proporcional a su importancia fisiológica y será en esos términos que la misma deberá ser analizada (Cuvier, 1798, p. 16 ). Al fin y al cabo, en las Leçons d'Anatomie Comparée, el propio Cuvier (1805, p. 58) nos decía que «manteniéndose siempre dentro de los límites que las condiciones necesarias de existencia prescribían, la naturaleza se abandona a toda su fecundidad en aquello en lo que tales condiciones no la limitan»; y, con toda seguridad, cuanto más singular sea esa variación, menos importante ella ha de ser en términos de organización.

El principio de las correlaciones, como aclara Piveteau (1961a, p. 487), no se aplica «con el mismo rigor en todas las direcciones»: «conforme nos alejamos de los órganos principales, aproximándonos de aquellos que lo son en menor grado», nos dice Cuvier (1805, p. 58), las variaciones morfológicas se multiplican; y «una vez que llegamos a la superficie, precisamente allí donde la naturaleza de las cosas quiso que fuesen colocadas las partes menos esenciales y cuya lesión es la menos peligrosa» la gama de variaciones efectivas se llega a parecer inagotable. Así, «sin apartarse jamás del pequeño número de combinaciones posibles entre las modificaciones esenciales de los órganos importantes», la naturaleza parece deleitarse al infinito en todas las partes accesorias»; $\mathrm{y}$ «no es preciso en este caso que una forma, que una disposición cualquiera, sea necesaria; a menudo hasta parece que para que la misma se realice no es preciso siquiera que ella sea útil: basta que ella sea posible, es decir, que no destruya el acuerdo del conjunto»(1805, p. 58).

No es, con todo, que Cuvier haya privilegiado la interioridad sobre la exterioridad del viviente por algún prejuicio logocéntrico (cfr. Cheug, 2000, p. 162 y p. 169): lo que él privilegiaba era el estudio de lo fisiológicamente determinante en cada tipo de organismo. Pero así, siguiéndose ese interés fundamentalmente fisiológico, se deja de lado precisamente el tópico que a Darwin (1859, pp. 3-4) iría a parecerle central: el de los múltiples detalles, generalmente contingentes desde una perspectiva fisiológica, que nos revelan las mutuas coadaptaciones de los seres orgánicos. Por mucho que lo busquemos, poco o nada encontramos en Cuvier que nos recuerde, ni por asomo, a los pormenorizados análisis de Darwin (1877) sobre las variadas tretas, contrivances, con que las orquídeas suelen facilitar su fecundación por parte de un insecto. Buscar, como Darwin (1859, p. 200) quería, una utilidad, un special use, "para cada detalle de estructura en toda criatura viviente» sería para Cuvier más un pasatiempo de naturalistas aficionados que asunto de genuina ciencia.

Más aún: algunas líneas de esos pasajes del capítulo VI del Origen de las Especies en los que Darwin (1859, p. 199) defiende su concepción utilitaria de las 
estructuras orgánicas pueden incluso parecer una respuesta a aquellos otros pasajes del Discours Préliminaire a las Recherches sur les ossements fossiles des quadrupèdes en los que Cuvier (1992 [1812] p. 113) ensaya una explicación para la variación intra-específica. En estos Cuvier pretende explicar esa variación considerándola efecto de factores ambientales inmediatos (como temperatura, luminosidad y composición y cantidad de las substancias que componen la dieta de organismo) que actuarían, directamente, sobre los procesos fisiológicos que ocurren en el organismo individual. Siendo, claro, «los caracteres más superficiales» los que más variarían en virtud de la intensidad de tales agentes: «el color debe mucho a la luz, el espesor del pelo al calon» y «el tamaño a la abundancia del alimento» (ver también Cuvier, 1798, pp. 10-11). Darwin (1859, p. 199), mientras tanto y entre otras cosas, intenta minimizar la importancia de esos factores para abrirle espacio a la selección natural.

Así, según esta tesis de Cuvier (1992 [1812], p. 114), «los elefantes serán mayores en tal o cual selva» en virtud de la disponibilidad de alimentos y los mismos «tendrán las defensas un poco más largas en los lugares donde el alimento sea más favorable a la formación de la materia del marfil». La hipótesis de que ese tamaño pueda variar justamente en virtud de su capacidad para operar como medio de defensa o lucha frente a predadores o a congéneres no es siquiera mencionada: está fuera de cuestión; y lo que se dice para el tamaño de los colmillos de los elefantes vale, según Cuvier, para el tamaño de los cuernos de renos y ciervos. Los mismos variarán en virtud de los elementos que integran la dieta de estos animales y no en virtud de los desafíos impuestos por el ambiente. Es de suponer, por eso, que Cuvier podría decir lo mismo de esas coloraciones que hoy, darwinianamente, tal vez explicaríamos en términos de mimetismo: las mismas se explicarían por la dieta y/o el efecto directo de la luz sobre el cuerpo de los organismos en cuestión. La biología de Cuvier era una biología de causas próximas.

«Por condiciones de existencia», lo dice bien Foucault (1994 [1970], p. 34), «Cuvier entendía la intersección de dos conjuntos: por un lado, el conjunto de las correlaciones que son fisiológicamente compatibles entre sí y, por otro lado, el medio en el cual el organismo vive». Pero ese medio, como Foucault (1994 [1970], p. 34) también apunta, se definía por la simple «naturaleza de las moléculas» que el organismo debía asimilar «ora por la respiración ora por la alimentación». Así, las variaciones en colores y tamaños que el darwinismo nos enseñó a interpretar como recursos adaptativos, para Cuvier no eran otra cosa que el resultado, ora de la calidad y cantidad de las moléculas que el organismo asimilaba por respiración y por alimentación, ora de la incidencia directa de un factor físico como la luz o la temperatura. Es decir: el medio, el entorno, era 
para Cuvier una cosa genérica como puede serlo un medio acuático o terrestre, una dieta herbívora o carnívora, un clima templado, húmedo, etc; y, en ese sentido, puede decirse que, para él, el entorno era algo vagamente más semejante al medio cósmico (milieu cosmique) bernardiano que a las condiciones de vida (conditions of life) darwinianas.

\section{UNA FISIOLOGÍA DE MUSEO}

La posteridad de Cuvier, podríamos por fin decir en una síntesis apretada de lo aquí expuesto, no está tanto en Darwin como en Claude Bernard. Más allá de su estrategia metodológica general y más allá de su lugar institucional, en el museo y no en el laboratorio, por medio de comparaciones anatómicas y no en base a experimentos, Cuvier, al igual que su contemporáneo Bichat (1994b, p. 293), quería producir una ciencia de causas próximas o secundarias: lo que hoy llamaríamos una biología funcional. Y si eso resulta un poco extraño es sólo porque se trata de una sugerencia que no encaja en la proyección hacia el pasado de esa dicotomía entre biología funcional y biología evolutiva que Mayr nos propone y que tantos, de un modo más o menos explícito, parecen aceptar. Proyección que aquí nos hemos permitido cuestionar.

Recordemos que, según ese modo de entender la historia de la biología, mientras la historia natural sería la base sobre la que se habría edificado, revolución darwiniana mediante, la actual biología evolutiva, la fisiología sería el elemento y el aporte fundamental de esa tradición médica que habría convergido en la constitución de la biología funcional como hoy la entendemos (Mayr, 1998a, p. 87; 1998b, p. 125). Con todo y como lo vimos, en la obra de Cuvier $(1810$, p. 201) la fisiología no sólo aparece formando parte de la histoire naturelle des corps vivans, sino que incluso es presentada como su parte más general y fundamental. La anatomía comparada sería, en la obra de Cuvier, la base de una biología funcional de museo y no de laboratorio; y esto tampoco encaja del todo bien con la contraposición entre ambos espacios que Mayr (1973) sugiere cuando vincula a los museos con el desarrollo de esa vertiente de las ciencias de la vida que, según su esquema de la historia de la biología, habría desembocado en la constitución de la biología evolutiva contemporánea.

Es necesario remarcar, sin embargo, que no estamos aquí ante ninguna rareza o peculiaridad de Cuvier. Lo que ocurre con la anatomía comparada de Cuvier ocurre también con la de Owen. Quien recorre las Hunterian Lectures in Comparative Anatomy de 1837 (Owen, 1992) constatará, no sólo la preocupación de este último «en fundar la anatomía comparada en la fisiología 
médica» (Sloan, 1992a, p. xiv), sino también su interés casi exclusivo en temas fisiológicos. Es más, en este caso, no sólo queda claro el interés fisiológico que guía a la anatomía comparada sino que, por una cuestión institucional, también queda más clara la conexión que esa disciplina podía tener con el conocimiento médico ( $c f r$. Sloan, 1992b, p. 10 y ss.).

Owen, médico cirujano de formación y profesión (López Piñero, 1992, p. 38; Sloan, 1992b, p. 10), habla desde un museo y no desde un laboratorio o un hospital, pero desde allí habla fundamentalmente para médicos y estudiantes de medicina (Sloan, 1992b, p. 47). Además, ese museo está instalado en el Royal College of Surgeons de Londres y la colección de anatomía comparada de cuya conservación Owen está encargado, había sido creada, precisamente, por John Hunter: un cirujano para el cual la anatomía comparada era una de las bases del conocimiento médico ( $c f r$. López Piñero, 1992, p. 14; Sloan, 1992b, p. 11). Y es como resultado de su trabajo en ese museo que Owen publica, entre 1833 y 1836, su Catalogue of physiological series of comparative anatomy (López Piñero, 1992, p. 38) ${ }^{10}$.

Es cierto de todos modos que, en general, la anatomía médica tendió a desarrollarse con independencia de la anatomía comparada (López Piñero, 1992, p. 8). Los círculos médicos, incluso, mostraron en general ciertas reticencias con relación a ese tipo de estudios. A mediados del siglo XVI, Vesalio había criticado a Galeno por extrapolar al hombre observaciones hechas sobre anímales (Cuvier, 1841, p. 45; López Piñero, 1992, p. 8, Pellegrin, 1992, p. 19); y, a fines del XVIII, Vicq de d'Azir debió refugiarse en el Jardin du Roi cuando la Facultad de Medicina de París le negó el anfiteatro para sus clases de anatomía comparada (López Piñero, 1992, p. 15). Siendo ese mismo espíritu zoófobo, además, el que podría explicar que, después de la muerte de Hunter, ocurrida en 1793, los cirujanos de Londres se hayan desentendido durante casi diez años de la valiosa colección que éste había dejado a los cuidados de William Clift (López Piñero, 1992, p. 14).

Por eso, aunque la anatomía comparada haya sido a menudo justificada como un recurso para que los estudiantes de medicina pudiesen estudiar fisiología (Appel, 1987, p. 47), lo cierto es que, salvo excepciones como las de John Hunter, Vicq de d'Azir, y el propio Owen, «la contribución de los médicos al desarrollo de los estudios comparados fue, en su conjunto, de poco relieve» (López Piñero, 1992, p. 14). Así, y como de hecho lo sabemos, esta disciplina en general se desarrolló en espacios institucionales ajenos a la pro-

10 En 1827 Owen fue nombrado ayudante del museo hunteriano y en 1836 fue nombrado conservador (López Piñero, 1992, p. 38). 
fesión y a la formación médicas (López Piñero, 1992, p. 9). Pero, si ese hecho subsidia, en cierto modo, el aspecto sociológico de la tesis de Mayr, aludo al innegable divorcio institucional entre la tradición médica y la tradición de los naturalistas que este subraya, el mismo es totalmente insuficiente para justificar su aspecto epistemológico; y con esto me refiero a la idea de que el desarrollo de la fisiología habría sido patrimonio de esa tradición.

El espacio institucional de la anatomía comparada pudo ser, hasta cierto punto y olvidando nada menos que a Hunter y a Owen, ajeno a la medicina. Sin embargo, eso no implica negar el interés eminentemente fisiológico que guiaba esa disciplina: la tradición médica nunca tuvo el monopolio de la fisiología; la misma fue también objeto de preocupación para autores que hoy catalogamos como naturalistas; y, por lo menos en el caso de Cuvier y Owen, se trataba de la preocupación central y de la justificación principal de la anatomía comparada. La distancia epistemológica entre el anfiteatro de anatomía y el museo era, quizá, menor de lo que Mayr parece sugerir, y esa distancia era, con seguridad, definitivamente más corta que la distancia institucional.

Tal es así que, trazando la historia de su disciplina, tanto Cuvier (1841, p. 4445) cuanto Owen (1992, pp. 142-143) se remitan a la propia tradición médica y, en particular, a uno de los sucesores de Vesalio en la cátedra de anatomía de Padua ${ }^{11}$. Me refiero, claro, a Girolamo Fabrizzi d'Aquapendente (López Piñero, 1992 p. 9). Sería él, según Cuvier (1841, p. 45), quien, a inicios del siglo XVII, habría descubierto el procedimiento metodológico específico de la anatomía comparada (Pellegrin, 1992, p. 18) ${ }^{12}$. En lugar de limitarse, como lo habían hecho Galeno y el propio Vesalio, a suplir con observaciones hechas sobre animales lo que no podían observar en humanos, Fabricio, nos dice Cuvier (1841, p. 45), se dedicó a «examinar a la vez el órgano correspondiente en el hombre y en los diversos animales», determinando lo que el mismo tenía de común y de diferente en cada una de las especies, y procurando establecer, a partir de ahí, «cuales eran las consecuencias de esas relaciones o de esas diferencias».

Siendo ese procedimiento, como Cuvier (1841, p. 45) destaca, «muy iluminador para las descripción de las funciones de cada órgano e incluso de cada parte de un órgano»; y es significativo que, a continuación, se pueda citar justa-

11 Vesalio deja Padua en 1543 y es sucedido, primero, por Realdo Colombo y luego por Gabriele Fallopia. Girolamo Fabrici toma el lugar de este último en 1562 (Grmek \& Bernabeo, 1997, p. 15; Senet, 1956, p. 19).

12 Esta parte de la Histoire des Sciences Naturelles en que Cuvier alude a la historia de la anatomía comparada es notablemente semejante a ciertos pasajes de la clase que Owen (1992, pp. 142-143) dictó el 6 de mayo de 1837 en el Hunterian Museum. 
mente los trabajos de William Harvey (1963 [1628], pp. 59-60) sobre la circulación sanguínea como uno de los resultados más importantes a que permitió llegar ese método comparativo pautado por Fabricio (Cuvier, 1841, p. 46). En efecto, Harvey, que fuera alumno de Fabricio (Grmek, 1990, p. 97) y que es también uno de los grandes nombres de la historia de la fisiología y de esa tradición médica a la que Mayr alude, usó y justificó el método comparativo como un recurso apto para determinar la función de los órganos dentro de la economía corporal (cfr. Harvey, 1963 [1628] pp. 44 y 45; Owen 1992 p. 143).

Harvey, al igual que Cuvier y Owen, también veía a la anatomía comparada como un método para producir conocimiento fisiológico; y su aplicación del método comparativo fue tan reconocida que Owen (1992, p. 143) se permitió decir que con él comienza la historia moderna de esa disciplina. Para Owen, como para Cuvier, la contraposición entre una tradición naturalista y una tradición médico-fisiológica hubiese sido definitivamente ininteligible. Después de todo, Owen (1973 [1860], p. 180) mismo considera a Cuvier un fisiólogo y este escogerá precisamente a un médico neurofisiólogo, aludo a Pierre Flourens, como su suplente en el College de France (Senet, 1956, p. 222). Con toda seguridad ni Owen ni Cuvier jamás hubiesen aceptado el hecho de que sus trabajos no sean considerados como contribuciones a esa genealogía de estudios fisiológicos que ellos remontaban a Fabricio y a Harvey.

\section{CONSIDERACIONES FINALES}

Pese a ello, y como ya lo hemos visto, así es como en general ocurre: ni el nombre de Cuvier ni el de Owen ocupan un lugar destacado, si es que ocupan alguno, en nuestras historias de la fisiología. Sin embargo, es pertinente reconocer que ese olvido no obedece al simple descuido de los historiadores; sino a razones que pueden ser encontradas en el propio devenir de la biología. Es el desarrollo de la ciencia, y no nuestra ingratitud, lo que explica, sin justificar, el modo en que actualmente consideramos la obra de estos autores.

La primera de esas razones tiene que ver con el hecho de que, pocos años después de la muerte de Cuvier, la aplicación del método experimental en fisiología haya comenzado a producir resultados cada vez más importantes y de más relevancia cognitiva que la mayor parte de los resultados producidos por la anatomía comparada (Jacob 1973 p. 201 y ss.; Coleman 1985 p. 269 y ss.) Los trabajos de Bernard, Müller, Liebig, Ludwig, Du Bois-Reymond y Helmholtz, no sólo llegaron mucho más lejos que los trabajos de Harvey, de Spallanzani, de Haller y 
de Lavoisier, sino que además llegaron mucho más lejos que los de Cuvier (cfr. Canguilhem 1961; Goodfield, J. 1987; Pichot 1993; Holmes 1999).

Las maquinarias vivientes fueron sistemáticamente desmontadas, la economía animal fue violentamente intervenida y manipulada, y esto, lejos de reducir al viviente a un caos ininteligible, permitió un conocimiento mucho más efectivo y significativo de su funcionamiento que aquel generado por la anatomía comparada. Así, muy rápidamente, esta disciplina se transformó, por decirlo de algún modo, en un recurso secundario, y hasta algo obsoleto, para la fisiología. La comparación anatómica podría sugerir hipótesis pero sólo el experimento las validaría. La fisiología podía ser también comparada o comparativa, pero lo sería no sólo observando sino experimentando sobre diferentes tipos de organismos (Bernard, 1984 [1865], p. 182 y 1878, p. 375; Dejours, 1997, p. 208).

Por otro lado, debido en gran parte al impacto de la teoría celular, el estudio del organismo acabó asumiendo un bies más histológico que morfológico (Russell, 1916, p. 246 y ss.; Albarracín Teulón, 1983, p. 241 y ss.). Más afín, en ese sentido, a Bichat que a Cuvier (Coleman, 1985, p. 41 y ss.; Duchesneau, 1999, p. 29 y ss.) Y eso también puede explicar el escaso impacto que la anatomía comparada tuvo en el desarrollo de la fisiología del siglo XIX: era en la constitución de los diferentes tejidos y no en las diferentes conformaciones de los órganos en donde había que buscar las claves últimas del funcionamiento orgánico (cfr. Bernard 1878 p. 247 y ss.). Según esa nueva perspectiva: «cuando un animal respira, son los glóbulos rojos de la sangre y las células del pulmón los que trabajan; cuando se mueve, trabajan las fibras de los músculos y los nervios; cuando segrega algo, trabajan las células de las glándulas» (Jacob 1973 p. 203). O dicho brevemente: «los órganos y los sistemas no existen por sí solos, sino gracias a las células que los constituyen y realizan sus funciones» (Jacob 1973 p. 203); y la ciencia de Cuvier era ciega para ese orden de fenómenos.

Pero lo curioso y lo que más ha confundido a los historiadores de la ciencia es el hecho de que al mismo tiempo en que los fisiólogos dejaron de considerar los resultados de la anatomía comparada como contribuciones positivas para su disciplina, los mismos cobraron una relevancia imprevista en tanto que premisas y evidencias pertinentes para el desarrollo de una disciplina cuya existencia para Cuvier era impensable. Aludo, claro, a eso que hoy llamamos biología evolutiva. Los datos de la anatomía comparada cuvieriana fueron producidos para una disciplina que, en cierto modo, prescindió de ellos; pero acabaron siendo fundamentales para el estudio de la genealogía de los formas vivas (Bowler, 1996, p. 40 y ss.) 
Mas aun: fue en esos datos en donde la idea de comunidad de descendencia encontró uno de sus argumentos más sólidos y convincentes; y fueron esos datos las evidencias fundamentales de las primeras reconstrucciones filogenéticas (Russell, 1916, p. 247; López Piñero, 1992, p. 44). Soslayada en los nuevos laboratorios de fisiología, la anatomía comparada no devino ella misma una pieza de museo o una reliquia: fue cooptada, sin beneficio de inventario, por una disciplina naciente que, además, se transformaría en la clave de toda la biología (Russell, 1916, p. 247). Y esos avatares de la anatomía comparada no pudieron dejar de afectar nuestra imagen de su supremo mentor.

Queriendo dar a la fisiología un método fértil y confiable, Cuvier contribuyó, malgré lui, a la consolidación de una perspectiva sobre lo viviente que a él, tal vez, le hubiese recordado demasiado a su colega Lamarck; y así, excluido del panteón de la fisiología en el cual con certeza hubiese querido ser admitido, el autor de las Lecciones de Anatomía Comparada ganó esa incomoda posición en la pre-historia de la biología evolutiva a la que aludíamos en el inicio de este trabajo. Posición que, por otra parte, se refuerza y se justifica por la condición de fundador de la paleontología que, no sin justicia, se suele adjudicar a Cuvier. Caprichos de la posteridad que, de todos modos, no podemos permitir que impidan una correcta comprensión de los objetivos cognitivos inherentes a su programa para la historia natural.

\section{BIBLIOGRAFÍA}

ADMUDSON, R. (1988), «Typology reconsidered: two doctrines on the history of evolutionary biology», en Biology \& Philosophy, 13: pp. 153-77.

Ameghino, F. (1915 [1884]), Filogenia, Buenos Aires, La Cultura Argentina.

Albarracín Teulón, A. (1983), La teoría celular: historia de un paradigma, Madrid, Alianza.

APPEL, T. (1987), The Cuvier-Geoffroy debate, Oxford, Oxford University Press.

Aristóteles (1994), Histoire des Animaux (trad. de Janine Bertier), París, Gallimard.

BALAN, B. (1979), L'ordre et le temps, París, Vrin.

Bates, M. (1990), The nature of natural history, Princeton, Princeton University Press.

BlanCKAERT, C. (1994), «Le Temp, grand ouvrier de la nature»; en Buffon: du grand livre de la nature à la grand galerie, París, Les Cahiers de Science \& Vie, pp. 58-73.

BERNARD, C. (1878), Leçons sur les phénomènes de la vie communs aux animaux et aux végétaux, París, Baillière et Fils. 
BERNARD, C. (1984[1865]), Introduction a l'étude de la médecine experimentale, París, Flammarion.

Bichat, X. (1994a [1800]), Première Partie de las Recherches physiologiques sur la vie et la mort ( $4^{\circ}$ ed., augmentée de notes par F. Magendie); en Bichat, X., Recherches physiologiques sur la vie et la mort (Première Partie) et autres textes, París, Flammarion [pp. 57-285].

BichAT, X., (1994b), Discours sur l'étude de la physiologie [Manuscrit inédit du vivant de Bichat]; en Bichat, X., Recherches physiologiques sur la vie et la mort (Première Partie) et autres textes, París, Flammarion [pp. 285-300].

Bock, W. \& WAHLERT, G. (1998), «Adaptation and the Form-Function Complex»; in C. Allen; M. Beckoff and G. Lauder, Nature's Purposes: analysis of function and design in biology, Cambridge, MIT Press [pp. 117-168].

Boutroux, E. (1949), De l'idée de loi naturelle dans la science et la philosophie contemporaines (cours professé a la Sorbonne en 1892-1893), París, Vrin.

Bowler, P. (1996), Life's Splendid Drama, Chicago, Chicago University Press.

Bowler, P. (1998), Historia Fontana de las ciencias ambientales, México, Fondo de Cultura Económica.

Buffetaut, E. (2001), Cuvier: le découvreur de mondes disparus (Col. Les Génies de la Science), París, Pour la Science.

BufFon G. (1749), «De la manière d'étudier et de traiter l'histoire naturelle», Premier discours de la Histoire naturelle genérale et particulière I, París, Imprimiere Royal [pp. 1-62].

CAPONI, G. (2002), «Explicación Seleccional y Explicación Funcional: la teleología en la biología contemporánea», Episteme, 14, pp. 57-88.

CAPONI, G. (2001a), «Biología Funcional vs. Biología Evolutiva», Episteme, 12, pp. 23-46.

CAPONI, G. (2001b), «Claude Bernard y los límites de la Fisiología Experimental». História, Ciências, Saúde, vol. 8 (2), pp. 375-406.

CAPONI, G. (2000), «Cómo y Por qué de lo Viviente», Ludus Vitalis, vol. VII (14), pp. 67-102.

CASSIRER, E. (1948), El problema del conocimiento en la filosofía y en la ciencia modernas IV: de la muerte de Hegel a nuestros días [1832-1932], México, Fondo de Cultura Económica.

CANguilhem, G. (1961), «La physiologie en Allemagne», en Taton, R. (1961), pp. 475-480.

Cheung, T. (2000), «De la peau chez Cuvier», Bulletin D'Histoire et D'Épistemologie des Sciences de la Vie VII, (2), pp. 161-170.

Coleman, W. (1985), La biología en el siglo XIX, México, Fondo de Cultura Económica.

Coleman, W. (2000), Georges Cuvier: zoologist, Cambridge, Harvard University Press.

CONRY, Y. (1974), L'Introduction du darwinisme en France au XIXe siècle, París, Vrin.

CORSI, P. (2001), Lamarck, París, CNRS. 


\section{GUSTAVO CAPONI}

CUVIER, G. (1798 (an 6), Tableau élémentaire de l'histoire naturelle des animaux, París, Baudouin.

Cuvier, G. (1810), Rapport Historique sur les progrès des Sciences Naturelles depuis 1789, et sur leur état actuel, París, L’Imprimerie Impériale.

CUVIER, G. (1817a), Le règne animal, París, Deterville.

CUVIER, G. (1817b), Mémoires pour servir a l'histoire et a l'anatomie des mollusques. Paris, Deterville.

CUVIER, G. (1861a), «Extrait d'un rapport sur l'état de l'histoire naturelle et ses accroissements depuis le retour de la paix maritime» [lu le 24 abril 1824]; en Recueil des éloges historiques lus dans les séances publiques de l'Institute de France, tome III, París, F. Didot [pp. 271-292].

Cuvier, G. (1861a), «Éloge de Lamarck» [lu le 27 juin 1831]; en Recueil des éloges historiques lus dans les séances publiques de l'Institute de France, tome III, París, F. Didot [pp. 179-210].

Cuvier, G. (1992[1812]), Discours Préliminaire a las Recherches sur les ossements fósiles de quadrupède, París, Flammarion.

CUVIER, G. (1805), Leçons d'anatomie comparée, París, Baudouin.

CuviER, G. (1841), Histoire des Sciences Naturelles, complétée, rédigée, annotée et publiée par M.Magdeleine de Saint-Agy, tome II, París, Fortin \& Masson.

CUVIER, G. «Essay on zoological analogies»; en ColEMAN, W. 1964 [pp. 189-190].

Cuvier, G. (1816), «Prospectus» del Dictionnaire des Sciences Naturelles, París, Deterville [pp. vi-vii]; apud COLEMAN, W. 1964 [pp. 24-25].

CUVIER, G. (1978), «Instrucciones sobre las investigaciones a realizar en torno de las diferencias anatómicas entre las varias razas humanas»; en C. Bilbao, La ciencia del hombre en el siglo XVIII. Buenos Aires, C.E.A.L. [pp. 57-61].

DARWIN, C. (1916 [1839]), Mi viaje alrededor del mundo (trad. de Journal of Researches into the Geology and Natural History of the various countries visited by H.M.S. Beagle por Constantino Piquer), Valencia, Prometeo.

DARWIN, C. (1859), On the Origin of Species, Londres, Murray.

DARWIN, C. (1877), The various contrivances by which orchids are fertilized by insects, second edition, Londres, Murray.

DAudin, H. (1926a), De Linné à Lamarck: Méthodes de la classification et idée de serie en botanique et en zoologie, París, F. Alcan.

DAUDIN, H. (1926b), Cuvier et Lamarck: les classes zoologiques et l'idée de série animale, vol. I: 1790-1830), París, F. Alcan.

DAUDIN, H. (1927), Cuvier et Lamarck: les classes zoologiques et l'idée de série animale, vol. II: 1790-1830), París, F. Alcan.

Dejours, P. (1997), «Le pouvoir explicatif de la physiologie comparée»; en C. Debru (ed.), Qu'est-ce que la physiologie?, París, Vrin [pp. 195-210]. 
Diderot, D. \& D'Alembert, J. (1999 [1751-1765]), L'Encyclopédie de Diderot et d'Alembert ou Dictionnaire raisonné des sciences, des arts et des métiers (CD-Rom). Marsanne, REDON.

DUCHESNEAU, F. (1999), «La structure normale et pathologique du vivant»; in M. Grmek (ed.): Histoire de la pensée médicale en Occident III (de le romantisme à science moderne), París, Seuil [pp. 29-58].

DURIS, P. (1994), «Classifier et Nommer». Buffon: du grand livre de la nature à la grand galerie, París, Les Cahiers de Science \& Vie [pp. 6-17]

Duris, P. \& GohaU, G. (1997), Histoire des sciences de la vie, París, Nathan.

Flourens, P. (1864), Examen du livre de M. Darwin sur l'origine des espèces, París, Garnier.

Foucault, M. (1968), Las palabras y las cosas, México, Siglo XXI.

Foucault, M. (1994 [1970]), «La situation de Cuvier dans l'histoire de la biologie»; en Dits et Écrits II: 1970-1975, París, Gallimard [pp. 30-66].

Galien [Galeno] (1994), De l'utilité des parties du corps humain (trad. de C. Daremberg et notes par A. Pichot), París, Gallimard.

GoHAu, G. (1974), «Método y sistema en la obra de Cuvier»; en Epistemología y Marxismo, Barcelona, Ed. Martínez Roca [pp. 82-100].

GoOFIELD, J. (1987), El desarrollo de la fisiología científica, México, UNAM.

Gould, S. (2003), «Da transmutação da lei de Boyle à revolução de Darwin»; en A. Fabian (ed.), Evolução: sociedade, ciência e universo, Baurú, EDUSC [pp. 11-40].

Gould, S. (2002), The structure of evolutionary theory, Cambridge, Harvard University Press.

Gould, S. (1999), La vida maravillosa, Barcelona, Crítica.

Gould, S. (1984), «Las antraconitas de Oeningen»; in Dientes de gallina y dedos de caballo, Blume, Barcelona [pp. 99-112].

GRANT, P. (2000), «What does it mean to be a naturalist at the end of the twentieth century?», The American Naturalist, 155, (1), pp. 1-12.

GREENE, J. (1979), «O paradigma Kuhniano e a revolução darwinista em história natural»; in História e Prática das Ciências, Lisboa, Regra do Jogo [p. 117-150].

GRIMOULT, C. (1998), Évolutionisme et fixisme en France (Histoire d'un combat: 18001882), París, CNRS.

Grmek, M. (1990), La Première Révolution Biologique, París, Payot.

GRMEK, M. \& BERNABEO, R. (1997), «La machine du corps», en GRMEK, M. (ed.); Histoire de la pensée médicale en Occident II (de la renaissance aux lumières), París, Seuil.

HARVEY, W. (1963[1628]), «Movement of the Heart and Blood in Animals: An Anatomical Essay»; en W. Harvey, The Circulation of Blood and other Writings (translated by K. Franklin). Londres, Dent \& Son [pp. 1-113]. 
Holmes, F. (1999), «La physiologie et la médecine expérimentale», en M. Grmek (ed.): Histoire de la pensée médicale en Occident III (de le romantisme à science moderne), París, Seuil [pp. 59-96].

Hull, D. (ed.) (1973), Darwin and His Critics, Chicago, The University of Chicago Press. JACOB, F. (1973), La lógica de lo viviente, Barcelona, Laia.

JANET, P. (1882), Les Causes Finales, Paris, Baillière.

KANT, E. (1992[1790]), Crítica de la facultad de juzgar, trad. de P. Oyarsún, Caracas, Monte Ávila.

Laudan, R. (1987), From Mineralogy to Geology, Chicago, The University of Chicago Press.

LAISSUS, Y. (1995), Le Muséum National d'Histoire Naturelle, París, Gallimard.

LAURENT, G. (2001), La naissance du transformisme: Lamarck entre Linné et Darwin. París, Vuibert/Adapt.

Le GuYADER, H. (1988), Theories et histoire en biologie, París, Vrin.

LE GuYADER, H. \& GÉNERMONT, J. (1998), «L'évolution: une histoire des idées»; en LE GuYAder, H. (ed.) L'évolution, París, Bibliothèque Pour la Science [pp. 4-10].

LEBrun, G. (1993), Kant e o fim da metafísica, São Paulo, Martin Fontes.

Ledesma Mateos, I. (2000), Historia de la Biología, México, AGT editor.

LENOIR, T. (1982), The strategy of life: teleology and mechanics in XIX century german biology, Chicago, Chicago University Press.

LIMOGES, C. (1976), La selección natural, México, Siglo XXI.

LITTRÉ, É. (1997 [1834]), «Cuvier et les ossements fossiles»; in La science au point de vue philosophique, París, Fayard [pp. 147-166].

LÓPEZ PIÑERO, J. (1992), La anatomía comparada antes y después del darwinismo, Madrid, Akal.

MAGner, L. (2002), A history of life sciences, NuevaYork, Dekker.

MAYR, E. (1998a), O desenvolvimento do pensamento biológico, Brasilia, UnB.

MAYR, E. (1998b), Asi es la biología, Madrid, Debate.

MAYR, E. (1988), Towards a new philosophy of biology, Cambridge, Harvard University Press.

MAYR, E. (1973), «Museums and Biological Laboratories», Brevioria, N.416 [1-7].

MCClellan, C. (2001), «The legacy of G. Cuvier in A. Comte's natural philosophy», in: Studies in History and Philosophy of Science, 32 (1), pp. 1-29.

MiLL, S. (1959 [1843]), A System of Logic, Longmans, Londres.

NoRDENSKIÖLD, E. 1949), Evolución histórica de las ciencias biológicas, Buenos Aires, Espasa Calpe.

Owen, R. (1992), The Hunterian Lectures in Comparative Anatomy [May and June 1837]; edited by P.R. Sloan, Londres, Natural History Museum Publications. 
OWEN, R. (1973 [1860]), «Darwin and the Origen of Species»; in Hull, D. (ed.) 1973 [pp. 175-213].

PAPP. D. (1980), Filosofía de las leyes naturales, Buenos Aires, Troquel.

Pellegrin, P. (1992), Présentation de Cuvier, G. (1992), [5-44].

Pichot, A. (1993), Histoire de la Notion de Vie, París, Gallimard.

PIVETEAU, J. (1961a), «Anatomie comparée des vertébrés»; en TATON, R. (1961), [p. 485-501].

Piveteau, J. (1961b), «Paleontologie des vertébrés»; en TATON, R. (1961), [p. 502-523].

RICQLES, A. (1996), Leçon inaugurale de la Chaire de Biologie Historique et Evolutionnisme (fait le Lundi 6 mai 1996), París, Collège de France.

Rostand, J. (1985 [1945]), Introducción a la historia de la biología, Barcelona, Planeta.

RUSE, M. (1983), La revolución darwinista, Madrid, Alianza.

RuSSELL, E. S. (1948), La finalidad de las actividades orgánicas, Buenos Aires, Espasa Calpe.

RUSSELL, E. S. (1916), Form and function, Londres, Murray.

SCHAFFner, K. (1993), Discovery and Explanation in Biology and Medicine, Chicago, The Univ. of Chicago Press.

SENET, A. (1956), L'homme a la découverte de son corps (roman de la physiologie), París, Plon.

SLOAN, P. (1992a), Preface to OwEN, R. 1992, [xiii-xvi].

SLOAN, P. (1992b), «On the edge of evolution»; Introductory Essay to OWEN, R. (1992), [1-72].

SMITH, C. (1977), El problema de la vida: ensayo sobre los orígenes del pensamiento biológico, Madrid, Alianza.

TATON, R. (ed.) (1961), La Science Contemporaine I // Le XIXe siècle, París, PUF.

TSCHERMAK, G. \& GeIKE, A. (1894), Historia Natural (tomo duodécimo: Mineralogía y Geología), Madrid, Montaner y Simón.

UeXKull, J. (1945 [1922]), Ideas para una concepción biológica del mundo, Buenos Aires, Espasa Calpe.

VON BAER, K. (1973 [1873]), «The Controversy over Darwinism»; en Hull, D. (ed.) 1973, pp. 416-425. 